\title{
Evaluating effects of land management on greenhouse gas fluxes and carbon balances in boreo-temperate lowland peatland systems
}

Neal R Haddaway ${ }^{1 *+}$, Annette Burden ${ }^{2 \dagger}$, Chris D Evans ${ }^{2}$, John R Healey ${ }^{3}$, Davey L Jones ${ }^{3}$, Sarah E Dalrymple ${ }^{4}$ and Andrew S Pullin ${ }^{1}$

\begin{abstract}
Background: Peatlands cover 2 to 5 percent of the global land area, while storing between 30 and 50 percent of all global soil carbon (C). Peatlands constitute a substantial sink of atmospheric carbon dioxide $\left(\mathrm{CO}_{2}\right)$ via photosynthesis and organic matter accumulation, but also release methane $\left(\mathrm{CH}_{4}\right)$, nitrous oxide $\left(\mathrm{N}_{2} \mathrm{O}\right)$, and $\mathrm{CO}_{2}$ through respiration, all of which are powerful greenhouse gases (GHGs). Lowland peats in boreo-temperate regions may store substantial amounts of $\mathrm{C}$ and are subject to disproportionately high land-use pressure. Whilst evidence on the impacts of different land management practices on C cycling and GHG fluxes in lowland peats does exist, these data have yet to be synthesised. Here we report on the results of a Collaboration for Environmental Evidence (CEE) systematic review of this evidence.
\end{abstract}

Methods: Evidence was collated through searches of literature databases, search engines, and organisational websites using tested search strings. Screening was performed on titles, abstracts and full texts using established inclusion criteria for population, intervention/exposure, comparator, and outcome key elements. Remaining relevant full texts were critically appraised and data extracted according to pre-defined strategies. Meta-analysis was performed where sufficient data were reported.

Results: Over 26,000 articles were identified from searches, and screening of obtainable full texts resulted in the inclusion of 93 relevant articles (110 independent studies). Critical appraisal excluded 39 studies, leaving 71 to proceed to synthesis. Results indicate that drainage increases $\mathrm{N}_{2} \mathrm{O}$ emission and the ecosystem respiration of $\mathrm{CO}_{2}$, but decreases $\mathrm{CH}_{4}$ emission. Secondly, naturally drier peats release more $\mathrm{N}_{2} \mathrm{O}$ than wetter soils. Finally, restoration increases $\mathrm{CH}_{4}$ release. Insufficient studies reported $\mathrm{C}$ cycling, preventing quantitative synthesis. No significant effect was identified in meta-analyses of the impact of drainage and restoration on DOC concentration.

Conclusions: Consistent patterns in $\mathrm{C}$ concentration and $\mathrm{GHG}$ release across the evidence-base may exist for certain land management practices: drainage increases $\mathrm{N}_{2} \mathrm{O}$ production and $\mathrm{CO}_{2}$ from respiration; drier peats release more $\mathrm{N}_{2} \mathrm{O}$ than wetter counterparts; and restoration increases $\mathrm{CH}_{4}$ emission. We identify several problems with the evidence-base; experimental design is often inconsistent between intervention and control samples, pseudoreplication is common, and variability measures are often unreported.

Keywords: Lowland, Boreo-temperate, Peat, Greenhouse gas, Carbon, Carbon dioxide, Methane, Nitrous oxide, Land management, Drainage, Restoration, Agriculture, Extraction

\footnotetext{
*Correspondence: neal_haddaway@hotmail.com

${ }^{\dagger}$ Equal contributors

'Centre for Evidence-Based Conservation, School of Environment, Natural

Resources and Geography, Bangor University, Bangor, Gwynedd LL57 2UW,

UK

Full list of author information is available at the end of the article
} 


\section{Background}

Peat and peatlands are composed of partly decomposed plant material deposited under saturated soil conditions. Peatland is a generic term including all types of peatcovered terrain and as a land cover class peatlands are a complex of swamps, bogs, and fens, sometimes called a "mire complex" [1]. 'Peatland' is sometimes taken to apply only to peat soils which retain their natural (peatforming) vegetation cover, but is applied here to any land-use on peat soils.

Peatlands are estimated to cover between 2 and 5 percent of the global land surface area while storing between 30 and 50 percent of all global soil carbon [2-4]. Whilst rates of $\mathrm{C}$ accumulation in peats are relatively low [5], they can continue to accumulate $\mathrm{C}$ over millennia, and exceed mineral soils in the length of time $C$ is stored [6].

$\mathrm{C}$ is sequestered into peatlands via photosynthetic uptake of carbon dioxide $\left(\mathrm{CO}_{2}\right)$. It then accumulates due to the slow decomposition rates of organic matter $(\mathrm{OM})$ in anaerobic conditions associated with high water tables. $\mathrm{C}$ loss can occur in a range of forms, of which the most important are gaseous $\mathrm{CO}_{2}$ and methane $\left(\mathrm{CH}_{4}\right)$, and dissolved $\mathrm{C}$, primarily dissolved organic carbon (DOC) and dissolved inorganic carbon (DIC). Low water tables associated with artificial drainage or natural dry periods are generally associated with net emission of $\mathrm{CO}_{2}$, whilst high water tables can result in significant emission of $\mathrm{CH}_{4}$ [7-11]. $\mathrm{CO}_{2}$ and $\mathrm{CH}_{4}$ are the two most important greenhouse gases (GHGs) [12,13] and peatlands may, therefore, contribute significantly to global GHG production under a changing climate [6]. In some peatlands, emission of nitrous oxide $\left(\mathrm{N}_{2} \mathrm{O}\right)$, which is a powerful GHG, may also be significant; this is typically associated with fertilisation, drainage and dry-rewet cycles e.g. [14].

This review was undertaken with the primary aim of evaluating land-management impacts on 'lowland peats' in England and Wales, in the United Kingdom (UK). In contrast to many boreo-temperate regions, the majority of the UK's peatland area is occupied by blanket bog, a peat type that forms in oceanic regions, and which therefore has a restricted global extent [15]. In the UK, blanket bogs occur extensively in upland high-rainfall areas, and comprise over $90 \%$ of the total peatland area of the country. Whilst large areas of blanket bog have indeed been modified by anthropogenic pressures, including drainage, managed burning, afforestation and grazing pressure, a high proportion of the total area nevertheless remains under natural or semi-natural vegetation. In contrast, although lowland peatlands (comprising lowland fen and lowland raised bog) occupy less than $10 \%$ of the overall UK peatland area, they are subject to disproportionately high levels of land-use pressure. Worrall et al. [16] estimated that over $70 \%$ of the total GHG emissions from peatlands were the result of land- use activities (arable cultivation, improved grassland and peat extraction) that are almost entirely associated with lowland peat, with an even higher proportion of peat GHG emissions within England associated with these activities. Despite this, relatively little research has been undertaken on lowland peats in the UK, and this review was therefore undertaken in order to assess the current evidence base relating to this peatland type. As the basis for this, it was considered that research undertaken on continental bogs and fens would be more analogous to UK lowland peats (in terms of both their functioning and the associated land-management activities) than UK blanket bogs, and studies from the wider boreal and temperate zones were therefore included in the review. As a consequence, the review may be considered applicable to boreo-temperate lowland peats in general, whilst excluding studies undertaken within blanket bogs and other peat types occurring in upland regions.

Lowland peats differ in many respects from the blanket mires of the uplands. Whereas blanket peat forms under conditions of high rainfall and low temperatures, lowland fens and raised bogs can form under drier and warmer conditions where natural drainage is poor. Consequently they tend to form only in flat areas, whereas blanket bogs can develop on areas of moderately undulating topography. Fens are characterised by the lateral input of water from groundwater or rivers, and have moderate to high levels of nutrients and low acidity. Raised bogs form low 'domes' of peat which are fed by rainwater, and which are therefore low in nutrients and are acidic. Natural vegetation in lowland peats may be quite different to that occurring in blanket bogs, particularly within fens where tall herb species and brown mosses may predominate, rather than the dwarf shrubs, low-growing sedges and Sphagnum mosses associated with bogs. Given these major differences in both the natural properties of lowland peats, and the different landuses to which they have been subjected it is doubtful whether data obtained from studies of upland blanket bogs can be extrapolated to lowland systems. The difficulty of quantifying C cycling and GHG fluxes for lowland peats is increased by their greater heterogeneity in terms of both typology and management, as well as their fragmented nature. Because of their importance for a wide range of ecosystem services (notably provisioning services such as food and water, but also cultural services such as access to natural landscapes in otherwise often highly developed regions, and regulating services such as flood control in some areas; Bonn et al. [17]), the role of lowland peats in climate regulation must be weighed against these other ecosystem services to enable appropriate management decisions.

Recent reviews of measurements of peatland $C$ stocks and GHG fluxes for the Department for the Environment, 
Food and Rural Affairs (Defra, UK) and the Joint Nature Conservation Committee (JNCC, UK), [16,18-20] have highlighted both the high degree of uncertainty in GHG flux estimates for lowland peats (in particular fens) and their high relative importance in terms of overall $\mathrm{C}$ and GHG emissions from peatlands. Worrall et al. [16] estimated that around 54\% of total GHG emissions from peatlands in the UK originate from lowland peats. On this basis, Evans et al. [20] suggested that the (few) existing studies on sites in lowland areas should be augmented in order to provide full C/GHG budgets, and that new measurement sites should be established in fens, particularly in areas under intensive agriculture, for which no existing flux measurement sites could be identified. A clear distinction was made in this assessment between emissions from sites undergoing a transition in land-use/management (which may lead, for example, to a short-term pulse of $\mathrm{CH}_{4}$ emission), and emissions from sites under stable long-term management.

Land use change over the past century has greatly altered many temperate and boreal lowland peatland ecosystems, favouring agriculture, forestry and peat extraction sites with artificially lowered water tables [21,22]. The Kyoto Protocol aims to mitigate GHG emissions [23], and restoration of peatlands via re-wetting has increasingly been identified as a potential means of doing so [24]. However, whilst a body of primary literature on the impacts of different land management practices on $\mathrm{C}$ cycling and GHG fluxes on lowland peats does exist, these data have yet to be synthesised. A previous systematic review has assessed the impact of drainage and rewetting on peat soils [25], but this review was undertaken in 2008, and focused on drainage and rewetting and included upland and lowland peats on a global scale. Here we report on the results of a Collaboration for Environmental Evidence (CEE) systematic review of the available evidence with regard to GHG emissions and C cycling on lowland peatlands under land management activities.

\section{Objective of the review}

\section{Primary question}

The primary question of this review was:

What is the impact of land management on GHG and C fluxes of boreo-temperate lowland peatland systems?

The question components were defined as follows: Population: Boreo-temperate lowland peat systems. Exposure: Areas with different long-term hydrological regimes.

or

Intervention: Draining and re-wetting/cessation of draining, extraction, conversion to agricultural production, agricultural or forestry practice.

Comparator: Control (with no intervention) or beforeafter studies or comparisons of areas with different management regimes over long periods of time, i.e. not short-term or seasonal changes.

Outcome: Net change (sequestration or release) in $\mathrm{C}$ or GHG balance, or net change of individual components of the C/GHG balance.

\section{Methods}

The systematic review question in hand was selected in order to provide an underpinning evidence base for a UK Department of Environment, Food and Rural Affairs (Defra) funded project to evaluate GHG flux and $\mathrm{C}$ balances of lowland peatland ecosystems in England and Wales. The review has been conducted alongside the establishment of a set of intensive C and GHG flux measurement sites under a range of land-management in England and Wales, with the joint aim of providing greater understanding and quantification of C/GHG emissions associated with different forms of land-use and management. A systematic review protocol was developed according to this research question, peer reviewed and posted in the CEE Library [26].

\section{Search strategy}

The search aimed to capture an unbiased and comprehensive sample of the literature relevant to the question, both published and unpublished. A number of different sources of information were searched in order to maximise coverage.

\section{Search terms}

Combinations of the following search terms (where * denotes a wild card that may represent zero or more characters and $\$$ represents zero or one character only) were applied to databases (Table 1).

As all databases and websites vary in the way they handle complex search strings and the use of Boolean operators, the exact search strings used differed between databases. Details of the different search terms used in each of the search facilities employed are provided in Additional file 1.

\section{Databases}

The following databases were searched using the terms detailed in Search terms:

1) ISI Web of Knowledge (inc. ISI Web of Science and ISI Proceedings)

2) Science Direct

3) Directory of Open Access Journals

4) Copac

5) Index to Theses Online

6) Agricola

7) CAB Abstracts

8) CSA Illumina/Proquest

9) Scopus 
Table 1 Habitat and outcome search terms

\begin{tabular}{|c|c|c|}
\hline $\begin{array}{l}\text { Habitat search } \\
\text { terms }\end{array}$ & $\begin{array}{l}\text { Outcome } \\
\text { search terms }\end{array}$ & $\begin{array}{l}\text { Intervention } \\
\text { search terms }\end{array}$ \\
\hline Aapa* & Accret* & Afforest* \\
\hline Bog* $^{*}$ & Accumulation & Arable \\
\hline Carr & Carbon & Cut\$over \\
\hline Fen\$ & $\mathrm{CH}_{4}$ & Cutt* \\
\hline Fenland & $\mathrm{CO}_{2}$ & Ditch* \\
\hline Histosol* & Depth & Drain* \\
\hline Hochmoortorf & DOC & Drought \\
\hline Mire & DOM & Extract* \\
\hline Mor & Erosion & Fertili* \\
\hline Muck & "GHG*" & Flood $^{*}$ \\
\hline Muskeg & "Green\$house gas*" & Forest $^{*}$ \\
\hline Niedermoortorf & Methane & Graz* \\
\hline Palsa & $\mathrm{N}_{2} \mathrm{O}$ & "Grip block" \\
\hline Peat* & Nitrous Oxide & Pastor* \\
\hline Pocosin* & "Organic content" & Pastur* \\
\hline Quag* & "Organic matter" & Plough* \\
\hline Sedge & Shrink* & Plow* \\
\hline Slough & SOM & Re\$veg* \\
\hline Suo & Subside* & Re\$wet* \\
\hline Swamp\$ & Wastage & Restor* \\
\hline Torfmoor & & Till* \\
\hline Tourbe & & Turf\$strip* \\
\hline \multicolumn{3}{|l|}{ Tourbièr* } \\
\hline Turvesuo & & \\
\hline
\end{tabular}

No time, language or document type restrictions were applied. References retrieved from the computerised databases were exported into a bibliographic software package (Endnote X3) and duplicates removed prior to assessment of relevance using inclusion criteria (Study inclusion).

\section{Search engines}

Searches of the following internet databases were performed:

http://scholar.google.com

http://www.Scirus.org (All journal and web sources)

Additional file 2 details the terms employed in these searches and the number and relevance of the hits returned. Assessments were limited to the first 50 hits returned for each search.

\section{Specialist sources}

Websites of the following relevant specialist organisations, identified during the planning stages of the review, were also searched for relevant material (see Table 2).
Websites were searched manually, by navigating through the site 'Publications' section, if available, and also by using any provided automated search with a number of key search terms. Details of the search terms employed for each website and the number and relevance of hits returned are provided in Additional file 3.

\section{Search comprehensiveness assessment}

The search results were tested for comprehensiveness in two ways. Firstly, a test library of eleven articles of known relevance was compared with search results to identify any missing sections of literature (see Additional file 1). Secondly, the bibliographies of seven reviews on the subject that were identified during searching were screened to identify potentially missed literature. Additional file 4 details the reviews that were screened and the results of the screening.

\section{Unobtainable/non-English language articles}

Articles that could not be obtained through subscription or open-access journals were obtained where possible by contacting authors with a request for proofs. Articles in foreign languages were screened at abstract using inhouse translators and online translation software, where possible. Articles that could not be obtained or translated at full text are detailed in Additional file 5.

\section{Study inclusion \\ Study screening}

Studies retained in the Endnote database from the search were screened for relevance in a three stage process. This process systematically removed studies that were not relevant or did not contain relevant information or data. At each stage, if there was insufficient information to exclude a study it was retained until the next stage.

In the first instance, the inclusion criteria identified below were applied to titles only in order to remove spurious citations. Articles remaining after this stage were subsequently screened by viewing the abstract and those remaining were also screened at full text.

To assess and limit the effects of between-reviewer differences in determining relevance, two reviewers $(A B$ and $\mathrm{SD}$ ) applied the inclusion criteria to a random sample of 90 articles at the abstract level. The kappa statistic $[27,28]$ was calculated, which measures the level of agreement between reviewers. After an initially low kappa score was obtained ( $k a p p a=0.356$ ), the reviewers discussed the discrepancies and clarified the interpretation of the inclusion criteria. Following this discussion, the inclusion criteria were applied by the two reviewers to the rest of the citations. 
Table 2 List of specialist organisations, the websites of which were searched for evidence

\begin{tabular}{|c|c|}
\hline \multicolumn{2}{|c|}{ Organisation Name } \\
\hline Agriculture And Agri Foods Canada & Ministry Of Natural Resources Of The Russian Federation \\
\hline Agri-Food And Biosciences Institute & Moorland Association \\
\hline Alterra & Moors For The Future \\
\hline British Association For Shooting And Conservation & National Council For Forest Research And Development (COFORD) \\
\hline Centre For Ecology And Hydrology & National Parks \\
\hline Countryside Council For Wales & National Soil Resources Institute \\
\hline Department Of Energy And Climate Change & National Trust \\
\hline Department For The Environment, Food And Rural Affairs & Natural England \\
\hline Dŵr Cymru/Welsh Water & Natural Resources Canada \\
\hline Environment Agency & Peat-Portal.Net \\
\hline Environment Canada & Plantlife UK \\
\hline Environmental Protection Agency & RAMSAR \\
\hline Environment Protection Agency Ireland & Royal Society For The Protection Of Birds \\
\hline EHS -Northern Ireland Environment Agency & Russian Guild Of Ecologists \\
\hline European Commission Joint Research Centre & Russian Regional Environmental Centre \\
\hline European Environment Agency & Severn Trent Water \\
\hline Finnish Peatland Society & Scottish Agricultural College \\
\hline Farmers Unions - UK & Scottish Executive \\
\hline Finland's Environmental Administration & Scottish Environment Protection Agency \\
\hline Finnish Environment Institute SYKE & Scottish Natural Heritage \\
\hline Food And Agriculture Organization Of The United Nations & Society For Ecological Restoration \\
\hline Forest Research & Society For Wetlands Scientists \\
\hline Forestry Commission & Tyndall Centre For Climate Change Research \\
\hline Global Environment Centre & UK Climate Impacts Programme \\
\hline Greenpeace & United Nations Environment Programme \\
\hline Intergovernmental Panel For Climate Change & United States Environment Protection Agency \\
\hline International Association For The Study Of The Commons & United Utilities \\
\hline International Mire Conservation Group & Welsh Assembly Government \\
\hline International Union For Conservation Of Nature & Wetlands International \\
\hline International Peat Society & Wildfowl And Wetlands Trust \\
\hline Irish Agriculture And Food Development Authority (Teagasc) & Wildlife Trusts UK \\
\hline Irish Peatland Conservation Council & World Wildlife Fund (organised by country) \\
\hline Joint Nature Conservation Committee & Yorkshire Water \\
\hline Macaulay Land Use Research Institute & \\
\hline
\end{tabular}

See Additional file 3 for details of the websites searched and search results.

\section{Inclusion criteria}

Each article was required to contain the following criteria in order to be included after each filter. However, in cases of uncertainty (including the absence of an abstract), the reviewer tended towards inclusion.

- Relevant population(s): Lowland peatland systems in temperate and boreal regions. In general, studies from outside the British Isles were considered to be from lowland-type peatlands (such as continental mires) unless specifically characterised as 'blanket bog' or associated with upland topographic locations.

- Exposure/intervention: Long-term re-wetting or draining of peat or peat related soils. Agricultural conversion of peat or peat-related soils. Afforestation of peat or peat-related soils. Agricultural or forestry management on peat or peat-related soils. Natural experiments comparing areas of peat or peat-related soils in the same region with different long term (not seasonal or sporadic) hydrology. 
- Types of comparator: Control or no intervention or before-after comparisons.

- Types of outcome: Amount of C or GHG stored in, sequestered or released from soils. Other physical measures of $\mathrm{C}$ loss or gain from peat or peat-related soils, e.g. erosion, efflux of DOC, subsidence and/or accumulation.

- Types of study: Any primary study including measures of C or GHG storage, sequestration or release from peat or peat-related soils. Studies that measured C or GHG storage, sequestration or release under laboratory conditions were excluded. Additionally, studies were only included if an intervention was administered for a period in excess of one year, so as to retain relevance and generalisability to the overall research aims of the review.

\section{Critical appraisal}

Individual studies that met the required inclusion criteria were subjected to critical appraisal. This process involved a detailed assessment of internal and external validity. Internal (the appropriateness of the experimental design in measuring the desired outcomes) and external (the generalisability of the study findings to the review question in hand) validity assessment included the extraction of a number of variables from included studies (see Table 3).

Once this information had been assessed for each article, a final judgment on study susceptibility to bias was made using all collated information in concert (see Additional file 6 for details of the information upon which this critical appraisal was based). Each study was classified as either 'low' or 'high' susceptibility to bias. Where insufficient detail was provided in study methodology, the category 'unclear' was given. Where design or methodology was considered to be significantly flawed, or where detail was lacking and flawed design implied, studies were excluded from further consideration. Studies with low external validity (i.e. generalisability to the review question in hand) were also excluded at this stage. Details of these excluded studies are provided in Additional file 7. Information extraction for critical appraisal was divided and carried out independently by two reviewers (NRH and $\mathrm{AB}$ ), and all excluded articles were discussed with additional advice from the Review Team (ASP, DLJ, CDE and JRH). All included studies were given susceptibility to bias categories by two reviewers (NRH and $\mathrm{AB}$ ), and agreement was assessed using a kappa test, which revealed substantial agreement between reviewers (Kappa statistic=0.61). Disagreements, particularly those between the 'low' and 'high' judgement groups, were discussed at length and a consensus agreed upon with the inclusion of advice from the Review Team where necessary.

\section{Data extraction}

\section{Data extraction strategy}

Data were extracted from included studies using a predefined form (Additional file 8), recording the mean, standard deviation, sample size, units, and notes for the study comparator and intervention. Pooled means and standard deviations were themselves calculated using a series of individual spreadsheets, which were populated with data from tables and figures of results from each article. The software DataThief [29] was used to extract data from figures.

Given the varied nature of data presentation in the included literature, a detailed protocol for data extraction was established in order to maintain consistency and transparency (see Additional file 8). Most importantly, whilst the use of pseudoreplicates (i.e. within sample replication as opposed to true replication of samples) is not ideal, the limited use of true replication within the evidence-base meant that spatial pseudoreplication (subsamples taken from within one sample where study sample size was very low) was used to estimate the variability in effect sizes (see Additional file 8 for details).

Potential reasons for heterogeneity were also extracted from studies (see Reasons for heterogeneity (subgroup analysis and meta-regression)):

\section{Data handling}

Extracted data were prepared for synthesis by producing effect sizes (raw mean difference). Raw mean difference $\bar{x}_{\text {intervention }}-\bar{x}_{\text {control }}$ was chosen since the effect size units are inherently meaningful. In order to perform metaanalysis with data measured in a variety of units, data for each measured outcome were converted to a com-

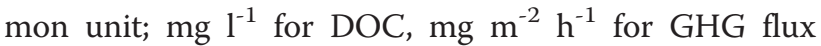
(where $\mathrm{mg}$ represents the whole molecule) and other units specified for individual outcome measures. Details of data extracted and how standard deviations were calculated can be found in Additional file 8.

Where GHG flux was reported as $\mathrm{CO}_{2}-\mathrm{C}, \mathrm{CH}_{4}-\mathrm{C}$ or $\mathrm{N}_{2} \mathrm{O}-\mathrm{N}$, data were converted to $\mathrm{CO}_{2}, \mathrm{CH}_{4}$ and $\mathrm{N}_{2} \mathrm{O}$ by applying a multiplication factor of 3.664, 1.336 and 1.571 respectively.

$\mathrm{CO}_{2}$ data were extracted in their commonly reported forms; ecosystem respiration $\left(\mathrm{R}_{\mathrm{eco}}\right)$ and net ecosystem exchange (NEE).

Summary effects from meta-analyses identifying significant patterns across studies were used to generate estimated summary effects in the units of $\mathrm{kg}$ or $\times 10^{3} \mathrm{~kg}$ (tonnes) of GHG flux per hectare per year. For $\mathrm{CH}_{4}$ and $\mathrm{N}_{2} \mathrm{O}$ these numbers were then used to calculate 100year global warming potentials (as adopted in the Kyoto Protocol; UNFCCC/CP/1997/7/Add.1/Decision 2/CP.3) by conversion into $\mathrm{CO}_{2}$ equivalents according to Forster et al. [30], using multiplication factors of 1 for $\mathrm{CO}_{2}, 25$ for $\mathrm{CH}_{4}$ and 298 for $\mathrm{N}_{2} \mathrm{O}$. 
Table 3 Variables assessed and criteria used for critical appraisal of included studies

\begin{tabular}{|c|c|c|c|}
\hline & & Low Susceptibility to Bias & High Susceptibility to Bias \\
\hline \multirow[t]{5}{*}{ Study design } & Study season, length & Long (>3 months) study period, multiple seasons & $\begin{array}{l}\text { Short ( }<3 \text { months) study period, winter } \\
\text { measurement }\end{array}$ \\
\hline & Intervention timescale & $\begin{array}{l}\text { Long-term intervention maintained for } \\
\text { multiple years }\end{array}$ & Intervention in place for $<2$ years \\
\hline & Replication, randomisation & $\begin{array}{l}\text { Replication at level of intervention, large sample } \\
\text { size }(>3) \text {, some degree of randomisation in } \\
\text { sample selection }\end{array}$ & $\begin{array}{l}\text { Pseudoreplicated, low sample size }(<3) \text {, } \\
\text { no randomisation }\end{array}$ \\
\hline & Control matching & $\begin{array}{l}\text { Control and treatment/exposure samples } \\
\text { well-matched (i.e. close in proximity but low } \\
\text { chance of spillover effects) }\end{array}$ & $\begin{array}{l}\text { No evidence of matching, potentially influential } \\
\text { differences between treatment and control }\end{array}$ \\
\hline & $\begin{array}{l}\text { Clarity and detail of } \\
\text { methods }\end{array}$ & General study design very clear and repeatable & Some missing information \\
\hline \multirow[t]{4}{*}{$\begin{array}{l}\text { Specific } \\
\text { methodology }\end{array}$} & $\begin{array}{l}\text { Eddy covariance } \\
\text { measurement details }\end{array}$ & $\begin{array}{l}\text { Full description of methodology, accounting } \\
\text { for wind direction/speed }\end{array}$ & $\begin{array}{l}\text { Some missing methodological detail, no } \\
\text { accounting for wind direction/speed }\end{array}$ \\
\hline & $\begin{array}{l}\text { Flux chamber measurement } \\
\text { details }\end{array}$ & $\begin{array}{l}\text { Full description of methodology, measurement } \\
\text { disturbance mitigation measures }\end{array}$ & $\begin{array}{l}\text { Some missing methodological detail, no mitigation } \\
\text { for measurement disturbance }\end{array}$ \\
\hline & $\begin{array}{l}\text { Soil porewater/air } \\
\text { measurement details }\end{array}$ & $\begin{array}{l}\text { Full description of methodology, representative } \\
\text { sampling }\end{array}$ & $\begin{array}{l}\text { Some missing methodological detail, sampling } \\
\text { unlikely to be representative of variability in } \\
\text { environment }\end{array}$ \\
\hline & $\begin{array}{l}\text { Surface water measurement } \\
\text { details }\end{array}$ & $\begin{array}{l}\text { Full description of methodology, representative } \\
\text { sampling }\end{array}$ & $\begin{array}{l}\text { Some missing methodological detail, sampling } \\
\text { unlikely to be representative of variability in } \\
\text { environment }\end{array}$ \\
\hline \multirow[t]{2}{*}{ Bias } & Potential measurement bias & Measurement bias unlikely or evidently not present & Bias likely as a result of methodology \\
\hline & Presence of confounders & $\begin{array}{l}\text { No obvious confounders stated or evident, or } \\
\text { stated but adequately accounted for }\end{array}$ & $\begin{array}{l}\text { Confounders stated and unaccounted for or likely } \\
\text { to be present }\end{array}$ \\
\hline
\end{tabular}

\section{Data synthesis \\ Interventions}

Groups of interventions and exposures were identified in an iterative process, with comparable studies retrospectively classed into one of 16 intervention/exposure groups, as detailed in Table 4.

\section{Narrative synthesis}

Tables of studies for each of the 16 intervention/exposure groups were arranged by measured outcome to display effect sizes and standard deviation along with summary descriptive data.

\section{Meta-analysis}

Where sufficient data existed, studies that reported means and variability were included in meta-analyses for the most common intervention/exposure groups by outcome. Meta-analysis was performed in the statistics package $\mathrm{R}$ [31] using the 'metafor' library [32] using the rma function. This function is equivalent to a random effects meta-analysis; a mixed effects model when moderators are included. Marginally significant test results $(0.075>\mathrm{p}$ $>0.050$ ) are reported for clarity, since thresholds for statistical significance are inherently arbitrary [33]. The presence of significant heterogeneity (i.e. differences between significant studies' results) was assessed using the test for residual heterogeneity (QE) [32]. In addition, forest plots [34] for each intervention/exposure group were produced for each outcome to display these data visually. Diagnostic plots to identify studies with strong influence on the inter study variability measure, $\mathrm{T}^{2}$, and the summary effect were plotted using the R library 'metafor' [32] and can be found in Additional file 9.

\section{Subgroup analysis}

Where sufficient data existed, subgroup analysis was performed by including susceptibility to bias judgement category (see Critical appraisal) in the meta-analysis using tests for moderators (QM, p-values and AIC) in the rma function of the 'metafor' library [32].

\section{Publication bias (funnel plots)}

The presence of potential publication bias was assessed for each intervention/exposure group by plotting study effect size against standard error. Asymmetry in both axes of the plot may suggest publication bias and was tested for with Egger's z-test. Funnel plots and egger's test results can be found in Additional file 9. 


\begin{tabular}{|c|c|}
\hline Intervention/exposure group & Definition \\
\hline Cropped-vs-bare & Actively cropped fields compared to those with no vegetation (extracted or de-vegetated) \\
\hline Drained and restored-vs-undrained & Drained and then restored peatlands compared to pristine fen \\
\hline Drained-vs-undrained & $\begin{array}{l}\text { Drained peatlands compared to pristine/undrained peats, or heavily drained peatlands } \\
\text { compared to lightly drained peats }\end{array}$ \\
\hline Dry-vs-wet & Dry peat soils compared to wetter soils \\
\hline Extracted and restored-vs-natural & Both extracted and then restored peats compared to unextracted/pristine peats \\
\hline High intensity farmed-vs-low intensity farmed & $\begin{array}{l}\text { Intensively compared with extensively farmed peats (in terms of a wide variety of unspecified } \\
\text { farming activities) }\end{array}$ \\
\hline Fertilised and grazed-vs-unfertilised and mown & Both fertilised and grazed compared to unfertilised and ungrazed but mown peats \\
\hline Fertilised-vs-less fertilised & High fertilisation rates compared to low fertilisation rates \\
\hline Grass-vs-forest & Grass fields compared to forested fields \\
\hline Grazed-vs-mown & Grazed peatlands compared to ungrazed but mown fields \\
\hline Irrigated-vs-non-irrigated & Rain fed irrigated peatlands compared to non-irrigated peats \\
\hline Mineral soil dressed-vs-undressed & Peats with added mineral soil compared to soils lacking mineral addition \\
\hline Old abandoned-vs-recently abandoned & Peats abandoned for a longer period compared to more recently abandoned peats \\
\hline Old afforested-vs-recently afforested & $\begin{array}{l}\text { Peats planted with trees for a longer period compared to more recently planted forest } \\
\text { peatlands }\end{array}$ \\
\hline Poor-vs-rich & $\begin{array}{l}\text { Peats described by authors as 'poor' compared to those described as 'rich' (corresponding to } \\
\text { natural gradients in nutrient status and acidity) }\end{array}$ \\
\hline Restored-vs-unrestored & $\begin{array}{l}\text { Previously extracted peats with deliberately raised water tables compared to extracted and } \\
\text { unaltered peatlands }\end{array}$ \\
\hline
\end{tabular}

\section{Reasons for heterogeneity (subgroup analysis and meta-regression)}

Potential sources of heterogeneity that were identified a priori during protocol development were; peat or peatrelated soil type (e.g. bog versus fen peats), depth of drainage, vegetation, annual mean temperature/rainfall, timescale of study, timescale of hydrological intervention, peat condition.

Studies that reported sufficient data to allow metaanalysis of measured outcomes within intervention/exposure groups were not sufficient in number nor sufficiently consistent in the reporting of sources of potential heterogeneity. This precluded meaningful subgroup analysis or meta-regression using these reasons for heterogeneity.

\section{Results}

\section{Review descriptive statistics}

Searches of literature databases identified 25,665 potentially relevant titles. Of these, 1,794 were assessed as relevant at the title-level and 229 at abstract-level screening. Eleven articles were unable to be translated and 79 articles could not be obtained at full text (see Additional file 5). Whilst efforts were made to contact the authors to request copies, 62 of these articles were published between 1973 and 2003, making successful contact with authors unlikely. After the addition of articles from other sources of searching, 93 articles were identified as relevant at full text screening. The 89 articles excluded as a result of full text screening, along with exclusion reasons, are identified in Additional file 7.

Figure 1 displays the different stages of the systematic review process and the number of articles and studies retained at each stage. Following full text assessment, data sources are referred to as studies rather than articles. This definition is important, since many articles report multiple studies. Here we define the unit of study as a geographically distinct study system. Hence, where different peatland systems were studied within the same article their results were treated as independent sample points. One hundred and ten individual studies were identified from the 93 included articles, and these studies were subjected to critical appraisal.

\section{Critical appraisal}

Critical appraisal of study internal and external validity resulted in the exclusion of 39 studies that, upon closer inspection, did not meet the inclusion criteria precisely and/or provided insufficient detail in their description of methodologies or results to warrant inclusion in any synthesis (see Additional file 7 for these excluded studies).

Of the 71 studies that were suitable for inclusion, 11 studies reported 19 outcome measures that were judged to be of high susceptibility to bias. Thirty-four studies reported 71 outcome measures that were judged to be of 


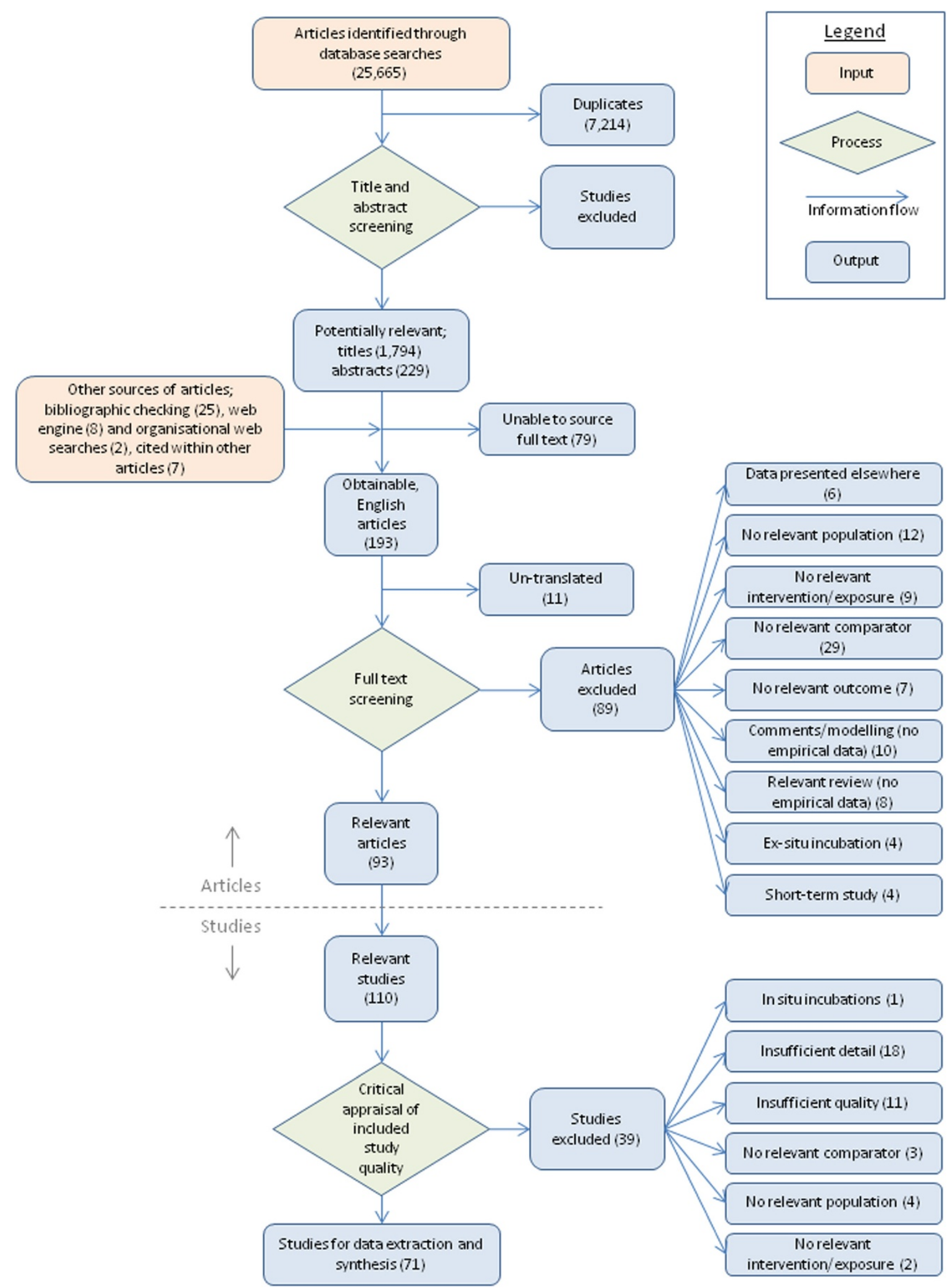

Figure 1 Schematic diagram of systematic review stages showing numbers of articles and studies retained at each phase. 
low susceptibility to bias. Twenty-seven studies reported 48 outcome measures that were judged to be of unclear susceptibility to bias (n.b. some studies reported multiple outcomes of different susceptibility to bias). Supporting information extracted from each study relating to the judgment for critical appraisal can be found in Additional file 6.

Some countries were very frequently studied. Finland and Canada were overwhelmingly the most studied countries, followed by the Netherlands and Germany with no other country exceeding three studies (Figure 2). Eleven regions were studied more than once (Figure 3), with Lakkasuo (in Finland) and Zegveld (in the Netherlands) being the most common.

Eleven studies employed full BACI (before-after-control-impacts) study designs, with one study BA (beforeafter), and the remaining studies all CI (control-impacts). The majority of studies used flux chambers to measure reported outcomes, with a very small number using eddy covariance and other less frequently employed methods. This is also reflected in the less frequently measured outcomes, e.g. subsidence measured via long-term peat depth records Figure 4. Figure 5 displays the period of included studies, showing that the majority of studies lasted less than 2 years.

\section{Synthesis}

Table 5 displays the numbers of outcome measures reported for different studies across the 16 intervention/ exposure groups. A number of intervention/exposure groups were represented by individual studies within each measured outcome, and quantitative synthesis of these studies' results is not feasible as a result of low commonality. These studies are described below in narrative syntheses, and where sufficient studies within outcomes allow, the impact of interventions/exposures is assessed quantitatively using meta-analysis. Effect sizes are all in $\mathrm{mg} \mathrm{m}^{-2} \mathrm{~h}^{-1}$ for $\mathrm{CO}_{2}, \mathrm{CH}_{4}$ and $\mathrm{N}_{2} \mathrm{O}$, and $\mathrm{mg} \mathrm{l}^{-1}$ for DOC unless otherwise stated.

Table 6 displays the number of studies with sufficient data for outcomes and groups with sufficient studies to allow meta-analysis (i.e. both mean and variability measure reported within the study and a total of more than three studies in one outcome per group). Drained versus undrained was the most frequent comparison, followed by restored versus unrestored and then high intensity versus low intensity farmed. Table 7 summarises the results of the meta-analyses carried out on these studies. The four outcomes with a greater significance than the conventional $\mathrm{p}<0.05$ threshold were; greater $\mathrm{R}_{\text {eco }}$ in drained compared to undrained, greater $\mathrm{CH}_{4}$ emission in restored compared to unrestored, and greater $\mathrm{N}_{2} \mathrm{O}$ emission in drained compared to undrained and in dry compared to wet peatlands (Table 5). There was also a marginally significant $(\mathrm{p}=0.055)$ effect of drainage on $\mathrm{CH}_{4}$ emission, and a marginally significant $(\mathrm{p}=0.051)$ effect of drainage on DOC.

\section{Studies reporting combined GHG outcomes}

Nine studies measured $\mathrm{CH}_{4}, \mathrm{~N}_{2} \mathrm{O}$ and $\mathrm{CO}_{2}$ emissions and fluxes together (see Table 8). Only one study, however, measured both NEE and $\mathrm{R}_{\text {eco }}$. This precluded a combined analysis of net 100-year global warming potential, since photosynthetic uptake of $\mathrm{CO}_{2}$ by plants

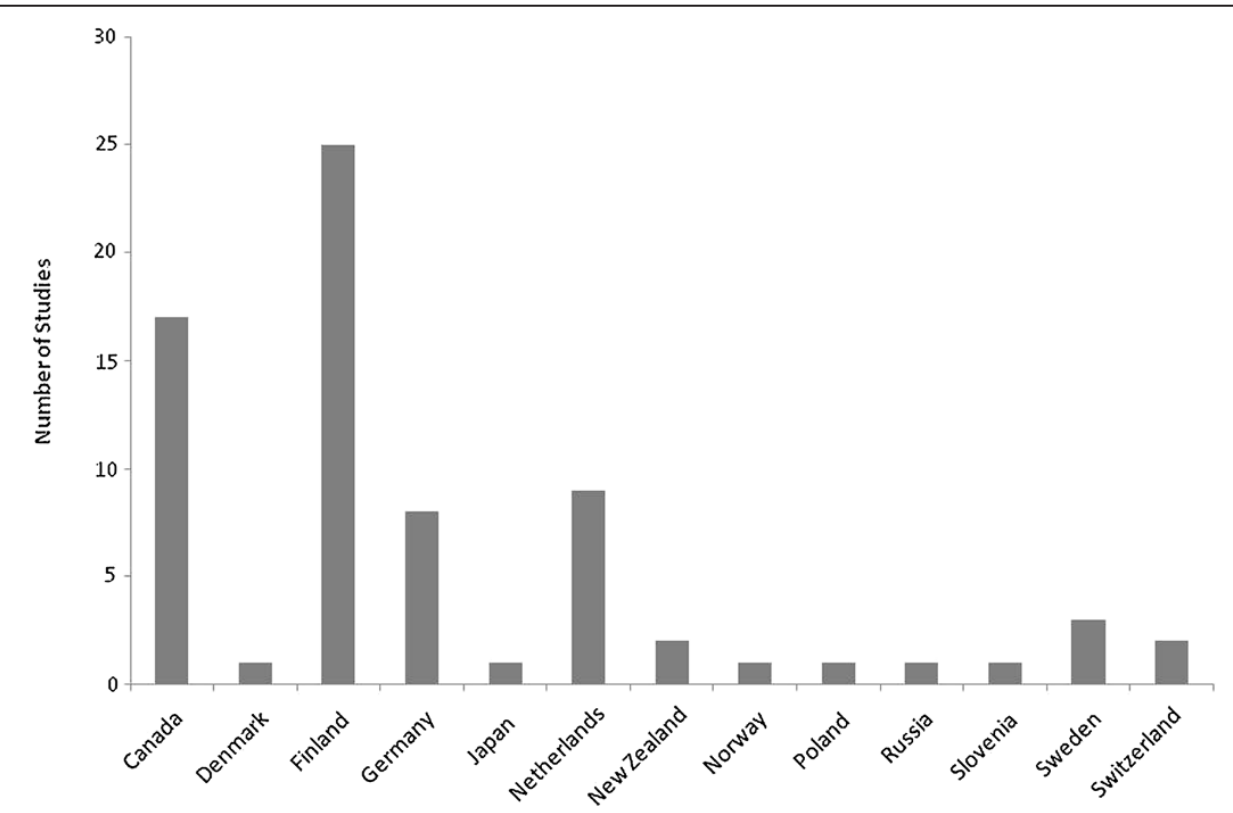

Figure 2 Frequency plot showing numbers of included studies undertaken in each country for all studies in the review. 


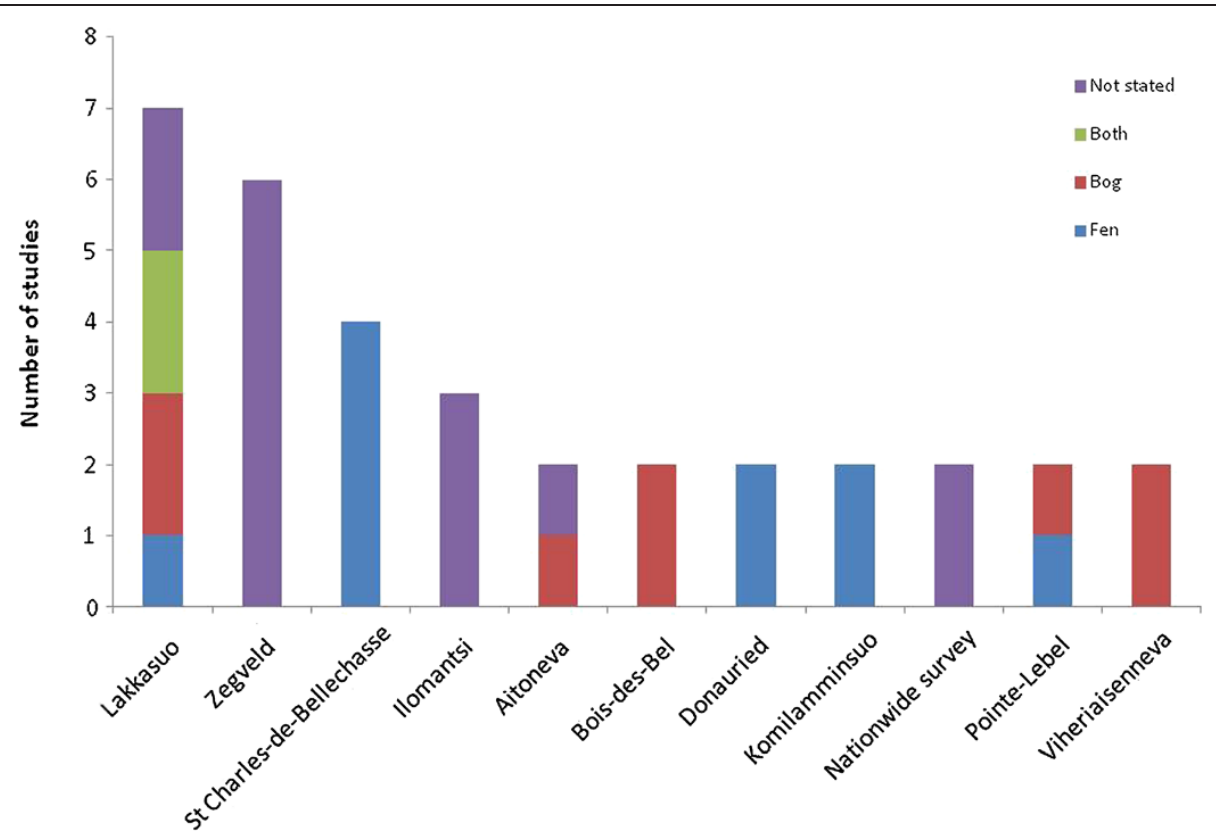

Figure 3 Frequency plot showing number of studies undertaken in each region for those regions studied more than once. Studies are separated by peat type; bog, fen, both bog and fen, and type not stated.

was unaccounted for in the remaining 8 studies. Furthermore, these studies' outcomes were not combined in a multivariate meta-analysis since the outcomes can be viewed as independent of one another.

Peat extraction and restoration interventions, and ground water level exposure

\section{Drained-vs-undrained}

Twenty-six studies reported a total of 48 outcomes dealing with drainage interventions. Meta-analyses were possible for NEE, $\mathrm{R}_{\text {eco }}, \mathrm{CH}_{4}, \mathrm{~N}_{2} \mathrm{O}$ and DOC. Only one study measured concentration of particulate organic carbon
(POC) and one study $\mathrm{C}$ stores. Both of these studies indicated lower levels following drainage, although POC effect size had a large variance (see narrative synthesis tables in Additional file 10).

Net ecosystem exchange (NEE) No significant patterns in NEE $\mathrm{CO}_{2}$ release were identified across the three synthesised studies (all of which were from Canada) for drained versus undrained peatlands (Table 7 and Figure 6). Significant heterogeneity was found, however, as suggested by the substantially higher flux figure for the Point-Lebel study of Strack et al. [42].

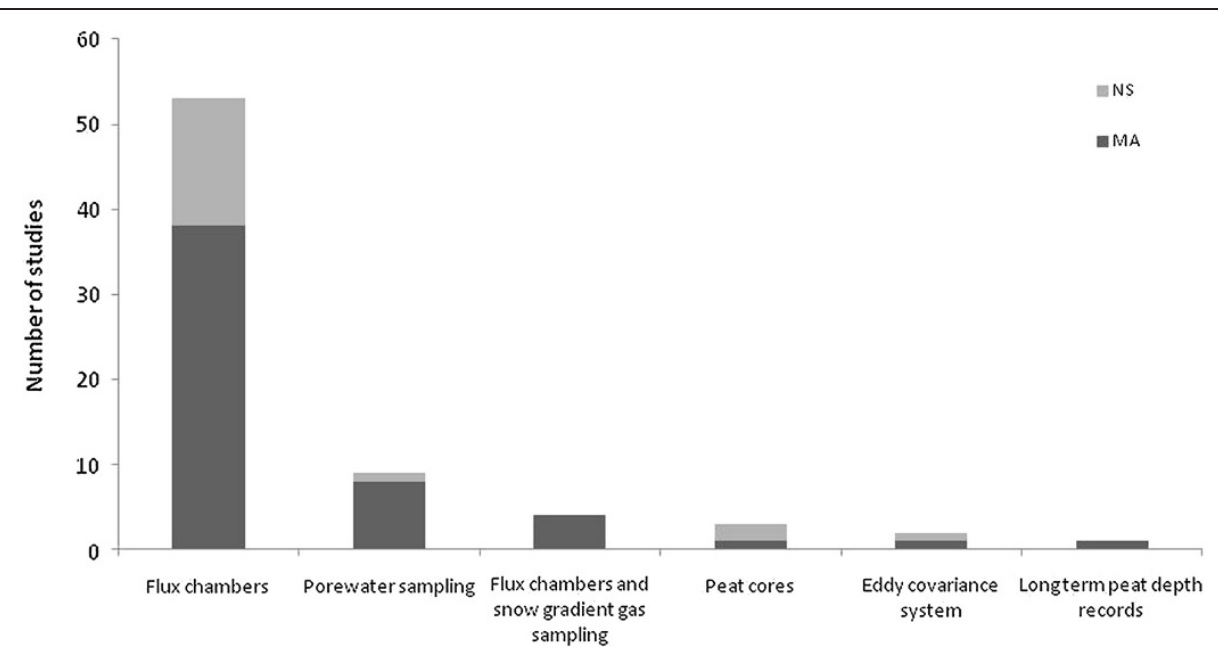

Figure 4 Frequency plot showing, number of studies using each method of carbon and greenhouse gas measurement found in the review, and availability of data suitable for meta-analysis. NS; narrative synthesis only, MA; meta-analysis. 


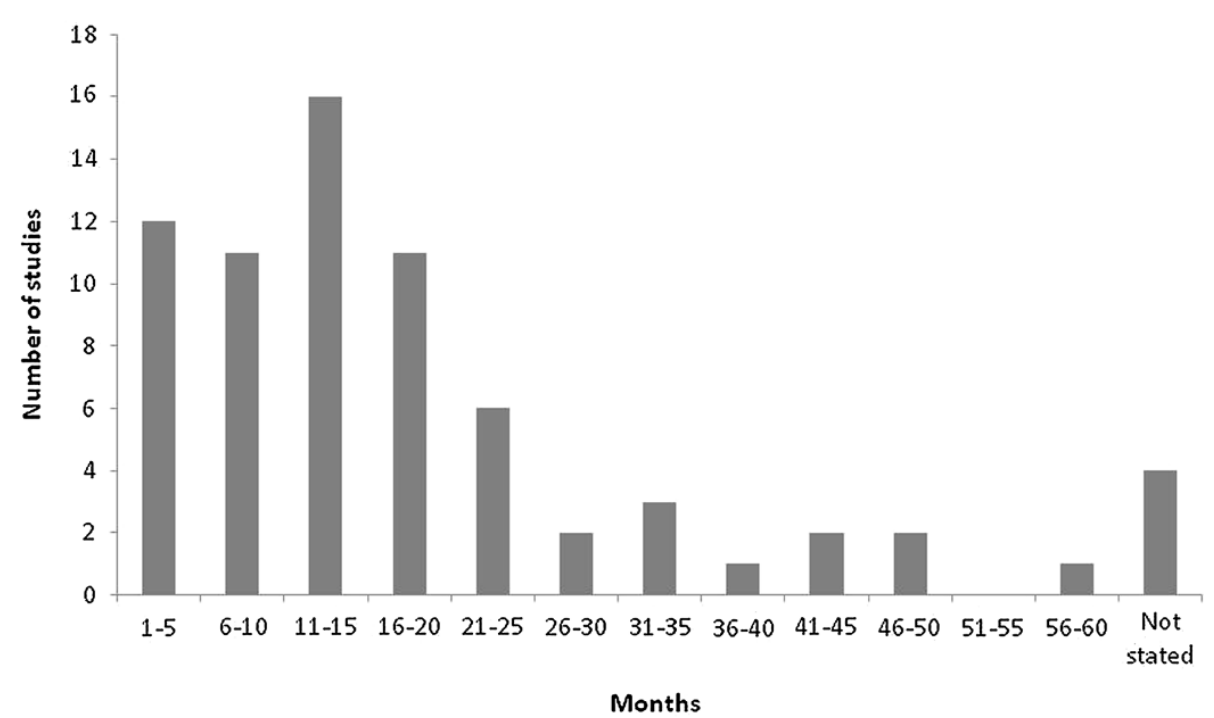

Figure 5 Frequency plot showing study length (total study months) for included studies.

Ecosystem respiration $\left(\boldsymbol{R}_{\text {eco }}\right)$ Drained peatlands released, on average, $125 \mathrm{mg} \mathrm{CO} \mathrm{m}^{-2} \mathrm{~h}^{-1}$ (95\% $\mathrm{CI}=6.71$ to 243) more $\mathrm{CO}_{2}$ through respiration than undrained peatlands, approximating to an annual difference of $11,000 \mathrm{~kg} \mathrm{CO} \mathrm{ha}^{-1}$ (95\% $\mathrm{CI}=0.588$ to 21.3 ) resulting from drainage $(\mathrm{p}=0.038)$ (Table 7 and Figure 7$)$. Studies varied considerably in their findings, shown clearly in the forest plot and by the presence of significant heterogeneity. Studies were undertaken over 4 [43], 6 [44], 12 [45], 15 [35], 16 [36,42], and 32 [46] months (study period not stated in [47]).

Five other studies reported mean $R_{\text {eco }}$ values but no measure of variability. Effect sizes ranged from -6.88 to $123 \mathrm{mg} \mathrm{m}^{-2} \mathrm{~h}^{-1}$ (see narrative synthesis tables in Additional file 10).

$\mathrm{CH}_{4}$ Drained peatlands may release $0.126 \mathrm{mg} \mathrm{CH}$ less than undrained peatlands per square metre per hour; equating to an approximate annual additional release of $11.0 \mathrm{~kg} \mathrm{CH}_{4} \mathrm{ha}^{-1}$ (95\% CI $=22.3$ to 0.263 ) and a 100 -year global warming potential difference of $276 \mathrm{~kg} \mathrm{CO}_{2}$ equivalents $\mathrm{ha}^{-1}$, although this result is only marginally significant $(p=0.055)$ (Table 7 and Figure 8). No significant heterogeneity between study results was identified. The results indicate an effect of $-0.126 \mathrm{mg} \mathrm{CH}_{4} \mathrm{~m}^{-2} \mathrm{~h}^{-1}(95 \%$ $\mathrm{CI}=-0.254$ to -0.003$)$. Studies were undertaken over 12 [45], 14 [48], 15 [10,35], 16 [36], 19 [49], and 32 [46] months (study period not stated in [47]).

Four studies could not be included in this metaanalysis due to missing measures of variability, but these studies all showed a negative effect of drainage (if only marginally); their mean effect sizes ranged from -0.047 to $-4.72 \mathrm{mg} \mathrm{m}^{-2} \mathrm{~h}^{-1}$ (see narrative synthesis tables in Additional file 10).
$\mathrm{N}_{2} \mathrm{O}$ Drained peatlands were found to release, on average, $0.008 \mathrm{mg} \mathrm{N}_{2} \mathrm{O} \mathrm{m}^{-2} \mathrm{~h}^{-1}$ (95\% $\mathrm{CI}=0.001$ to 0.016 ) more on drained peatlands relative to undrained peatlands $(\mathrm{p}=0.033)$ (Table 7 and Figure 9), corresponding to an approximate annual excess of $0.701 \mathrm{~kg} \mathrm{~N}_{2} \mathrm{O} \mathrm{ha} \mathrm{ha}^{-1}$ (95\% $\mathrm{CI}=0.088$ to 1.40 ), and a 100 -year global warming potential difference of $209 \mathrm{~kg} \mathrm{CO}_{2}$ equivalents $\mathrm{ha}^{-1}$. No significant heterogeneity in study results was identified. Only Nykanen et al. [10] studied peatlands under active agricultural management, possibly accounting for the high variability in $\mathrm{N}_{2} \mathrm{O}$ emission measured. Studies were undertaken over 9 [41], 15 [10,35], 16 [36], and 32 [46] months.

Five studies reported mean $\mathrm{N}_{2} \mathrm{O}$ emission but no measure of variability, but these effects were positive (4 studies, effect sizes ranged from 0.004 to $0.227 \mathrm{mg} \mathrm{m}^{-2} \mathrm{~h}^{-1}$ ) or undetectable ( 1 study) (see narrative synthesis tables in Additional file 10).

DOC Drained peatlands possessed, on average, a greater concentration of porewater DOC of $27.3 \mathrm{mg} \mathrm{l}^{-1}(95 \%$ $\mathrm{CI}=-0.099$ to 54.7$)$ relative to undrained peatlands, although this result was only marginally significant $(\mathrm{p}=0.051)$ (Table 7 and Figure 10). Significant heterogeneity existed between studies, indicating that a source of variation in study results was present and unaccounted for. Studies were undertaken over 2 [50], 6 [51,52], and 25 [53] months (study period not stated in [54]).

\section{Restoration (Drained and restored-vs-undrained,} restored-vs-unrestored, extracted and restored-vs-natural) Seventeen studies reported a total of 26 outcomes for restoration interventions. Only $\mathrm{CH}_{4}$ and $\mathrm{R}_{\text {eco }}$ emission, 
Table 5 Measured outcomes within studies falling into the 16 intervention/exposure groups tabulated across 11 outcomes

\begin{tabular}{|c|c|c|c|c|c|c|c|c|c|c|c|c|}
\hline $\begin{array}{l}\text { Intervention/exposure-vs- } \\
\text { comparator }\end{array}$ & $\begin{array}{l}\mathrm{NEE} \\
\mathrm{CO}_{2} \\
\end{array}$ & $\begin{array}{l}\mathrm{R}_{\text {eco }} \\
\mathrm{CO}_{2} \\
\end{array}$ & $\mathrm{CH}_{4}$ & $\begin{array}{c}\mathrm{CH}_{4} \text { pore } \\
\text { water }\end{array}$ & $\mathrm{N}_{2} \mathrm{O}$ & $\begin{array}{c}\text { Soil air } \\
\mathrm{N}_{2} \mathrm{O}\end{array}$ & $\begin{array}{l}\text { Soil surface } \\
\quad \mathrm{N}_{2} \mathrm{O}\end{array}$ & C stores & DOC & SOC & POC (TOC-DOC) & $\begin{array}{c}\text { Long-term } \\
\text { subsidence }\end{array}$ \\
\hline Cropped-vs-bare & & 2 & 3 & & 1 & & & & & & & \\
\hline $\begin{array}{l}\text { Drained and restored-vs- } \\
\text { undrained }\end{array}$ & 1 & 1 & & & & & & & & & & \\
\hline Drained-vs-undrained & 3 & 15 & 13 & & 10 & & & 1 & 5 & & 1 & \\
\hline Dry-vs-wet & 2 & 2 & 2 & & 3 & & & & & & & \\
\hline $\begin{array}{l}\text { Extracted and restored-vs- } \\
\text { natural }\end{array}$ & 1 & 1 & & & & & & & & & & \\
\hline $\begin{array}{l}\text { High intensity farmed-vs-low } \\
\text { intensity farmed }\end{array}$ & & 3 & 5 & & 6 & & & 1 & 1 & 1 & & 1 \\
\hline $\begin{array}{l}\text { Fertilised and grazed-vs- } \\
\text { unfertilised and mown }\end{array}$ & & & & & 1 & & & & & & & \\
\hline Fertilised-vs-less fertilised & 2 & 3 & 3 & & 6 & & & & & & & \\
\hline Grass-vs-forest & & 1 & 1 & & 1 & 1 & & & & & & \\
\hline Grazed-vs-mown & & & 3 & & 1 & & & & & & & \\
\hline Irrigated-vs-non-irrigated & & & & & 1 & & 1 & & & & & \\
\hline $\begin{array}{l}\text { Mineral soil dressed-vs- } \\
\text { undressed }\end{array}$ & & & & & 1 & & & & & & & \\
\hline $\begin{array}{l}\text { Old abandoned-vs-recently } \\
\text { abandoned }\end{array}$ & & 1 & & & & & & & & & & \\
\hline $\begin{array}{l}\text { Old afforested-vs-recently } \\
\text { afforested }\end{array}$ & & 1 & 1 & & 1 & & & & & & & \\
\hline Poor-vs-rich & & 1 & 1 & & & & & & 2 & & & \\
\hline Restored-vs-unrestored & & 6 & 4 & 1 & 1 & & & & 8 & & 1 & \\
\hline
\end{tabular}

$\mathrm{NEE}=$ net ecosystem exchange $\mathrm{CO}_{2}, \mathrm{R}_{\text {eco }}=$ ecosystem respiration $\mathrm{CO}_{2}, \mathrm{DOC}=$ dissolved organic carbon, SOC=soil organic carbon, $\mathrm{POC}=$ particulate organic carbon (total organic carbon (TOC) - DOC).

and DOC concentration outcomes had sufficient data reported to permit meaningful meta-analysis.

Ecosystem respiration $\left(\boldsymbol{R}_{\text {eco }}\right.$ ) Restoration was found to have no significant effect on $R_{\text {eco }}$ (Table 7 and Figure 11). No heterogeneity between studies was found, although this result was marginal.

One other study provided means but no variability [51]. This study compared restored with unrestored peatlands using three different comparisons; restored-vs-actively

Table 6 Study results across outcomes for key intervention/exposure groups

\begin{tabular}{llllll}
\hline Intervention/exposure-vs-comparator & $\mathbf{C H}_{\mathbf{4}}$ & $\mathbf{N}_{\mathbf{2}} \mathbf{O}$ & $\mathbf{N E E}$ & $\mathbf{R}_{\text {eco }}$ & $\mathbf{D O C}$ \\
\hline Drained-vs-undrained & 9 & 5 & 3 & 10 & 5 \\
Dry-vs-wet & & 3 & & & \\
High intensity farmed-vs-low & 5 & 6 & & & \\
intensity farmed & & & & & \\
Grazed-vs-mown & 3 & & & & \\
Restored-vs-unrestored & 4 & & 3 & 8
\end{tabular}

Numbers refer to those studies with sufficient data (i.e. mean and variability measure) and quantities of studies to allow meta-analysis (i.e. $>3$ ). NEE=net ecosystem exchange $\mathrm{CO}_{2}, \mathrm{R}_{\text {eco }}=$ ecosystem respiration $\mathrm{CO}_{2}$. harvested, closed-ditch restored-vs-abandoned, and inundated restored-vs-abandoned. The former restoredvs-harvested comparison yielded a positive effect, whilst the latter two restored-vs-abandoned had large negative effects.

Two studies compared drained and restored peatlands with 'natural' or undrained peatlands. Both studies found negative effect sizes of $-37.5 \pm 85.4$ (SD) $\mathrm{mg} \mathrm{m}^{-2} \mathrm{~h}^{-1}$ [55] and $-101 \pm 110$ (SD) $\mathrm{mg} \mathrm{m}^{-2} \mathrm{~h}^{-1}$, indicating that the drained and restored peatlands released less $\mathrm{CO}_{2}$ from respiration than undrained/'natural' peatlands.

$\mathrm{CH}_{4}$ Restoration resulted in an increase in emission of $0.248 \mathrm{mg} \mathrm{CH} \mathrm{m}^{-2} \mathrm{~h}^{-1}$ (95\% $\mathrm{CI}=0.052$ to 0.446$)$ $(\mathrm{p}=0.014)$ (Table 7 and Figure 12), corresponding to $21.7 \mathrm{~kg} \mathrm{ha}^{-1}$ annually (95\% CI=4.56 to 39.1 ) and $543 \mathrm{~kg}$ $\mathrm{CO}_{2}$ equivalents $\mathrm{ha}^{-1}$. Studies showed no identifiable heterogeneity. Studies were undertaken over 16 [56,57] and 43 months [58].

This finding was supported by higher concentrations of pore water $\mathrm{CH}_{4}$ in restored peatlands reported by Waddington and Day [58]. 
Table 7 Test results for random effects meta-analyses for five intervention/exposure categories with sufficient data

\begin{tabular}{|c|c|c|c|c|c|c|c|c|c|c|}
\hline $\begin{array}{l}\text { Intervention/exposure- } \\
\text { vs-comparator }\end{array}$ & $\begin{array}{l}\text { Measured } \\
\text { outcome }\end{array}$ & No. studies & SEE $^{1}$ & SE & Lower $95 \% \mathrm{Cl}$ & Upper $95 \% \mathrm{Cl}$ & Description & p-value* & $\mathrm{T}^{2}( \pm \mathrm{SE})$ & $\begin{array}{l}\text { Test for } \\
\text { Heterogeneity; } \\
Q_{\text {(df), }} \text { p-value }\end{array}$ \\
\hline \multirow[t]{5}{*}{ Drained-vs-undrained } & NEE & 3 & 116 & 161 & -200 & 431 & Greater in drained & 0.473 & $7.40 \times 10^{3}\left( \pm 77.8 \times 10^{3}\right)$ & $85.3_{(2),}<0.001$ \\
\hline & $\mathrm{R}_{\text {eco }}$ & 10 & 125 & 60.2 & 6.71 & 243 & Greater in drained & $0.038^{*}$ & $31.1 \times 10^{3}\left( \pm 16.9 \times 10^{3}\right)$ & $150_{(9),}<0.001$ \\
\hline & $\mathrm{CH}_{4}$ & 9 & -0.126 & 0.066 & -0.254 & 0.003 & Greater in undrained & 0.055 & $0.000( \pm 0.016)$ & $12.8_{(8),}, 0.119$ \\
\hline & $\mathrm{N}_{2} \mathrm{O}$ & 5 & 0.008 & 0.004 & 0.001 & 0.016 & Greater in drained & $0.033^{*}$ & $0.000( \pm 0.0001)$ & $2.33_{(4),}, 0.676$ \\
\hline & DOC & 5 & 27.3 & 14.0 & -0.099 & 54.7 & Greater in drained & 0.051 & $839( \pm 677)$ & $134_{(4),}<0.001$ \\
\hline Dry-vs-wet & $\mathrm{N}_{2} \mathrm{O}$ & 3 & 0.221 & 0.103 & 0.019 & 0.424 & Greater in dry & $0.032^{*}$ & $0.018( \pm 0.032)$ & $5.46_{(2)}, 0.065$ \\
\hline Grazed-vs-mown & $\mathrm{CH}_{4}$ & 3 & -5.39 & 4.40 & -14.0 & 3.23 & Greater in grazed & 0.220 & $44.4( \pm 58.8)$ & $8.71_{(2),}, 0.013$ \\
\hline \multirow[t]{3}{*}{ Restored-vs-unrestored } & $R_{\text {eco }}$ & 3 & 48.7 & 104 & -155 & 253 & Greater in restored & 0.640 & $20.0 \times 10^{3}\left( \pm 33.7 \times 10^{3}\right)$ & $5.89_{(2)}, 0.053$ \\
\hline & $\mathrm{CH}_{4}$ & 4 & 0.248 & 0.101 & 0.052 & 0.446 & Greater in restored & $0.014^{*}$ & $0.000( \pm 0.053)$ & $1.18_{(3),}, 0.759$ \\
\hline & DOC & 6 & 15.6 & 11.6 & -7.20 & 38.3 & Greater in restored & 0.180 & $622( \pm 497)$ & $26.1_{(5),}<0.001$ \\
\hline \multirow{2}{*}{$\begin{array}{l}\text { High intensity } \\
\text { farmed-vs-low } \\
\text { intensity farmed }\end{array}$} & $\mathrm{CH}_{4}$ & 4 & -0.004 & 0.004 & -0.011 & 0.004 & $\begin{array}{l}\text { Greater in low } \\
\text { intensity farmed }\end{array}$ & 0.349 & $0.000( \pm 0.0003)$ & $3.51_{(3),}, 0.314$ \\
\hline & $\mathrm{N}_{2} \mathrm{O}$ & 5 & 0.143 & 0.100 & -0.053 & 0.340 & $\begin{array}{l}\text { Greater in high } \\
\text { intensity farmed }\end{array}$ & 0.153 & $0.043( \pm 0.035)$ & $18.0_{(4),}, 0.001$ \\
\hline
\end{tabular}

${ }^{1}$ Units: $\mathrm{CH}_{4}=\mathrm{mg} \mathrm{CH}_{4} \mathrm{~m}^{-2} \mathrm{~h}^{-1}$, DOC=mg l-1 $\mathrm{N}_{2} \mathrm{O}=\mathrm{mg} \mathrm{N}_{2} \mathrm{O} \mathrm{m}{ }^{-2} \mathrm{~h}^{-1}$, NEE and $\mathrm{R}_{\text {eco }}=\mathrm{mg} \mathrm{CO}_{2} \mathrm{~m}^{-2} \mathrm{~h}^{-1}$.

Negative 'summary effect estimates' indicate a greater value for the control than the intervention and vice versa. $\mathrm{SEE}=$ summary effect estimate. $\mathrm{SE}=$ standard error, $\mathrm{Cl}=\mathrm{confidence}$ interval, $\mathrm{T}^{2}=\mathrm{estimate}$ of tau-squared, inter-study variability. ${ }^{\prime \prime \prime}$ indicates significance at $\mathrm{a}=0.05,{ }^{\prime \prime}$ ' indicates marginal significance. $\mathrm{NEE}=$ net ecosystem exchange $\mathrm{CO}_{2}, \mathrm{R}_{\mathrm{eco}}=$ ecosystem respiration $\mathrm{CO}_{2}$, $\mathrm{DOC}=$ dissolved organic carbon. 
Table 8 Studies measuring emissions/fluxes of all three GHGs together

\begin{tabular}{lll}
\hline Study & Region & Measured outcomes \\
\hline Danevcic et al. [35] & Ljubljana & $\mathrm{CH}_{4}, \mathrm{~N}_{2} \mathrm{O}, \mathrm{CO}_{2}\left(\mathrm{R}_{\text {eco }}\right)$ \\
Klove et al. [36] & Bodin & $\mathrm{CH}_{4}, \mathrm{~N}_{2} \mathrm{O}, \mathrm{CO}_{2}\left(\mathrm{R}_{\text {eco }}\right)$ \\
Lund et al. [37] & Fajemyr & $\begin{array}{l}\mathrm{CH}_{4}, \mathrm{~N}_{2} \mathrm{O}, \mathrm{CO}_{2} \\
\left(\mathrm{R}_{\text {eco }} \text { and NEE) }\right.\end{array}$ \\
Maljanen et al. [38] & Western Finland & $\mathrm{CH}_{4}, \mathrm{~N}_{2} \mathrm{O}, \mathrm{CO}_{2}\left(\mathrm{R}_{\text {eco }}\right)$ \\
Maljanen et al. [39] & Kannus & $\mathrm{CH}_{4}, \mathrm{~N}_{2} \mathrm{O}($ air and soil), \\
Martikainen et al. [10] & Lakkasuo & $\mathrm{CO}_{2}\left(\mathrm{R}_{\text {eco }}\right)$ \\
Nykanen et al. [10] & Ilomantsi & $\mathrm{CH}_{4}, \mathrm{~N}_{2} \mathrm{O}, \mathrm{CO}_{2}\left(\mathrm{R}_{\text {eco }}\right)$ \\
Petersen et al. [40] & Nationwide survey & $\mathrm{CH}_{4}, \mathrm{~N}_{2} \mathrm{O}, \mathrm{CO}_{2}\left(\mathrm{R}_{\text {eco }}\right)$ \\
Von Arnold et al. [41] & Asa & $\mathrm{CH}_{2} \mathrm{O}, \mathrm{CO}_{2}\left(\mathrm{R}_{\text {eco }}\right)$ \\
\hline
\end{tabular}

DOC No significant effect on DOC concentration of restored versus unrestored peatlands was apparent across the included studies (Table 7 and Figure 13). Significant heterogeneity was identified, however, with the three studies in River-de-Loup having particularly large variability around their effect sizes.

Two studies did not report variability about their means for DOC; they showed both positive [59, 22.8 $\left.\mathrm{mg} \mathrm{l}^{-1}\right]$ and negative $\left[60,-28.8 \mathrm{mg} \mathrm{l}^{-1}\right]$ effects. The former study fails to describe the restoration time scale, whilst the latter investigated a peatland that had been drained in the $19^{\text {th }}$ Century and rewetted in 1984, 20 years prior to the study.
Other measured outcomes Two studies reported net ecosystem exchange $\left(\mathrm{CO}_{2}\right)$ for drained and restored peatlands relative to undrained/'natural' peatlands. These studies found positive effect sizes of $42.2 \pm 145$ (SD) $\mathrm{mg} \mathrm{m}^{-2} \mathrm{~h}^{-1}$ [55] and $289 \pm 161$ (SD) $\mathrm{mg} \mathrm{m}^{-2} \mathrm{~h}^{-1}$ [61]. One study found a small negative effect of restoration on drained peatlands of $-0.006 \mathrm{mg} \mathrm{N}_{2} \mathrm{O} \mathrm{m}^{-2} \mathrm{~h}^{-1}$ [62]. Finally, one study reported a negative effect size of $-5.67 \mathrm{mg} \mathrm{l}^{-1}$ in concentration of $\mathrm{POC}$ as a result of restoration of drained peatlands [53].

\section{Dry-vs-wet}

Three studies reported mean and variability measures for $\mathrm{N}_{2} \mathrm{O}$ emission on dry and wet peatlands; whilst a range of other measured outcomes were reported in a small number of studies.

$\mathrm{N}_{2} \mathrm{O}$ Drier peat released $0.221 \mathrm{mg} \mathrm{N}_{2} \mathrm{O} \mathrm{m} \mathrm{m}^{-2} \mathrm{~h}^{-1}(95 \%$ $\mathrm{CI}=0.019$ to 0.424$)$ more than wet peat $(\mathrm{p}=0.032)$ (Table 7 and Figure 14), corresponding to an approximate annual difference of $19.4 \mathrm{~kg} \mathrm{~N}_{2} \mathrm{O} \mathrm{ha}{ }^{-1}$ (95\% CI=1.66 to 37.1) and 5.77 tonnes of $\mathrm{CO}_{2}$ equivalents ha ${ }^{-1}$. However, whilst the results are from three different studies, the data are collected from the same peatland area. Furthermore, during the critical appraisal process, these studies were classified as unclear $[63,64]$ and high $[65]$ in their susceptibility to bias. The results should therefore be treated with caution. No heterogeneity was evident, although the result is marginal, a possible concern given the small number of studies in the analysis. However, the consistency between this result and the comparison of $\mathrm{N}_{2} \mathrm{O}$ emissions from drained and

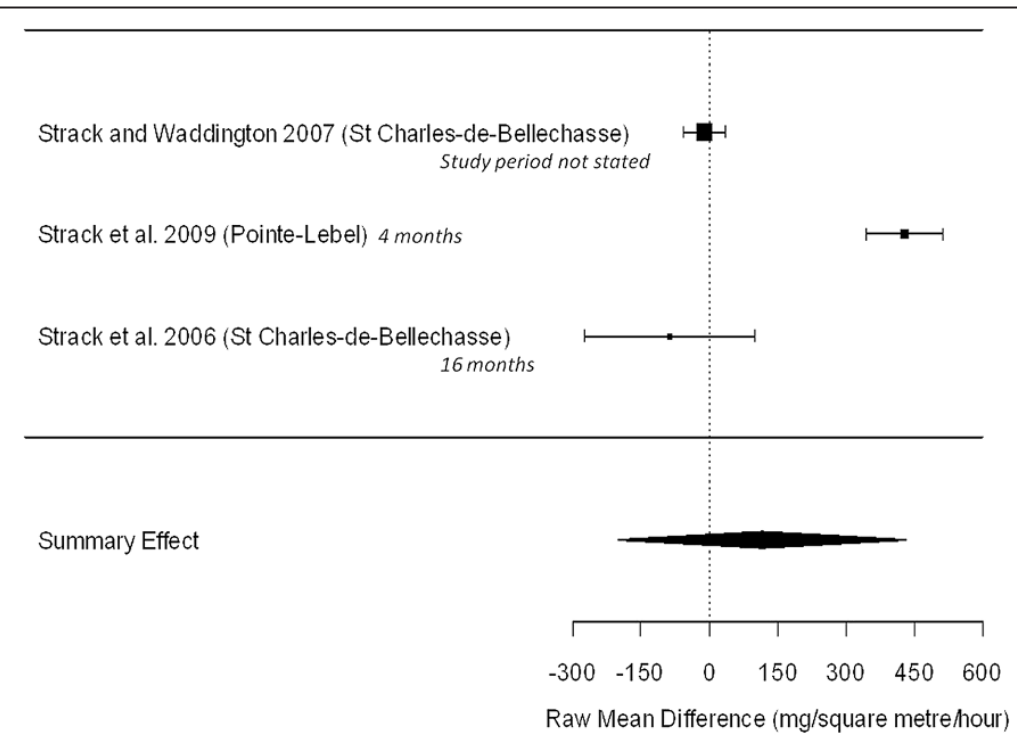

Figure 6 Forest plot of meta-analysis of effect sizes (raw mean difference) comparing net ecosystem exchange $\left(\mathrm{NEE} \mathrm{CO}_{2}\right)$ in drained versus undrained peatlands. The dashed line represents no effect. Size of boxes represents the weight of the study in the analysis. Horizontal lines represent 95\% confidence intervals. Positive effect sizes indicate greater flux of $\mathrm{CO}_{2}$ in drained peatlands than undrained controls. The position of the centre of the diamond represents the overall summary effect (a weighted average) and its horizontal extent represents the positive and negative $95 \%$ confidence intervals. 


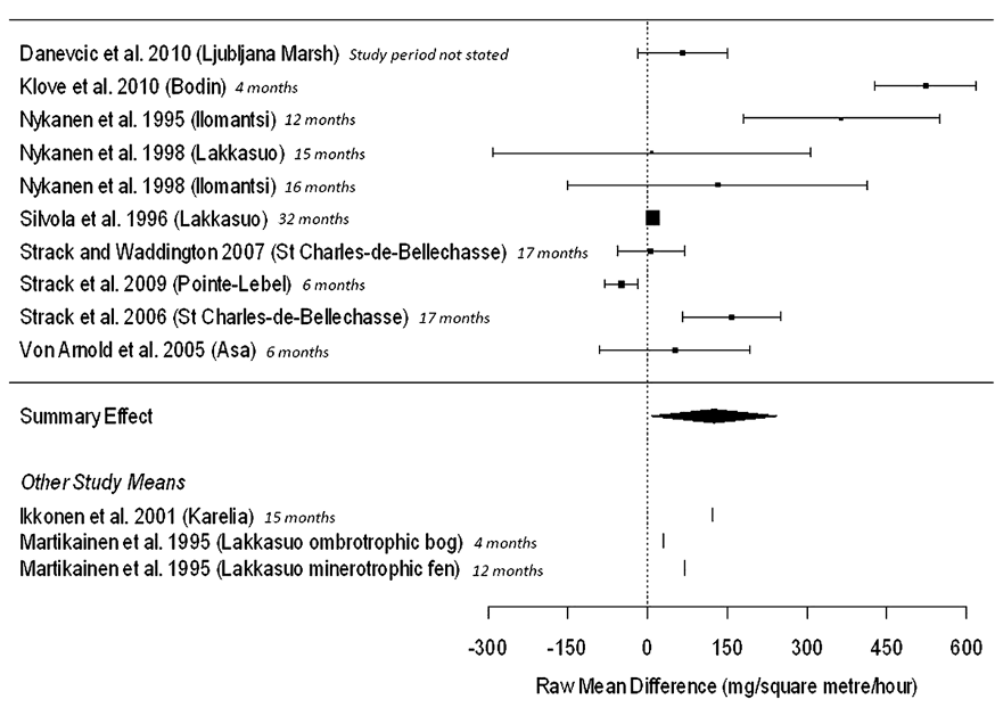

Figure 7 Forest plot of meta-analysis of effect sizes (raw mean difference) comparing total ecosystem respiration ( $\left.R_{\text {eco }}\right)$ in drained versus undrained peatlands. The dashed line represents no effect. Size of boxes represents the weight of the study in the analysis. Horizontal lines represent $95 \%$ confidence intervals. Positive effect sizes indicate greater flux of $\mathrm{CO}_{2}$ in drained peatlands than undrained controls. The position of the centre of the diamond represents the overall summary effect (a weighted average) and its horizontal extent represents the positive and negative 95\% confidence intervals. Other Study Means are provided for studies where a measure of variability could not be extracted.

undrained peatlands provides some confidence that the results may reflect a genuine pattern. Studies were undertaken over 9 [65], 19 [64], and 25 [63] months.

Other measured outcomes Four studies reported comparisons of dry versus wet peatlands across three other outcomes. Methane was found to be released in greater quantities from wet peats; effect size $=-0.003 \pm 0.005$ (SD) $\mathrm{mg}$ $\mathrm{m}^{-2} \mathrm{~h}^{-1}$ [66], Hedges $\mathrm{d}=-2.081 \pm 0.412$ (SD) [67]. Two studies found lower NEE in dry peats than wet peats; one reporting only a mean [68] and the other reporting wide variability about a small effect size [61]. Finally, two studies reported

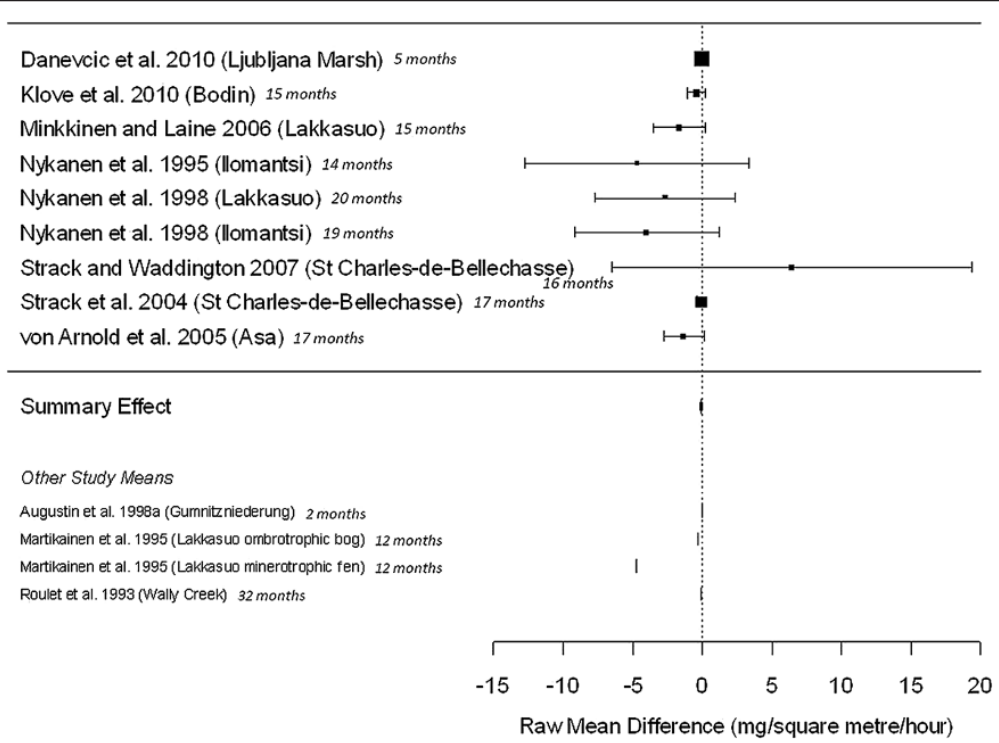

Figure 8 Forest plot of meta-analysis of effect sizes (raw mean difference) comparing $\mathrm{CH}_{4}$ from drained versus undrained peatlands. The dashed line represents no effect. Size of boxes represents the weight of the study in the analysis. Horizontal lines represent $95 \%$ confidence intervals. Positive effect sizes indicate greater flux from drained peatlands than undrained controls. In the Summary Effect row, the position of the centre of the diamond represents the overall summary effect (a weighted average) and its horizontal extent represents the positive and negative 95\% confidence intervals. Other Study Means are provided for studies where a measure of variability could not be extracted. 


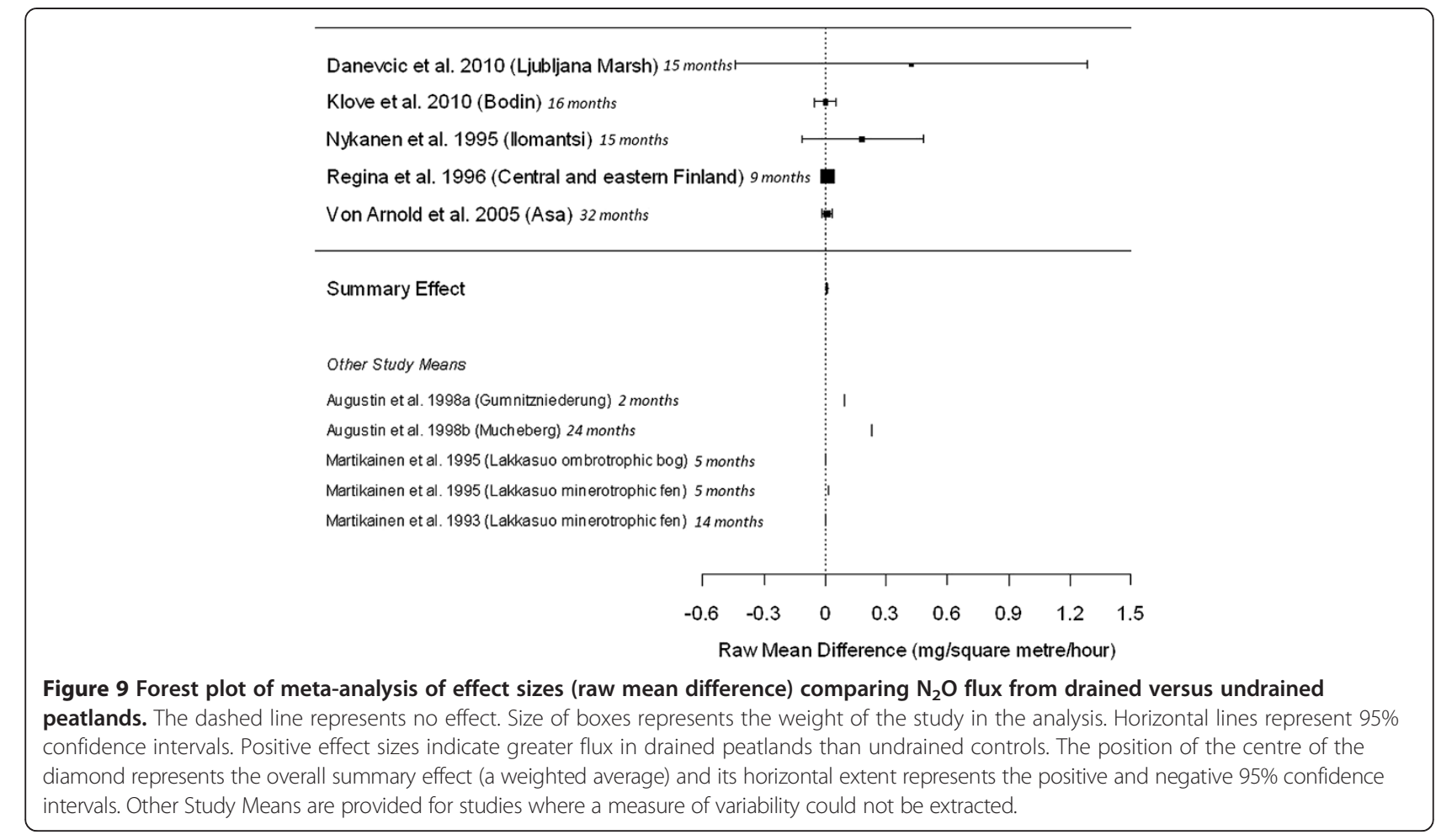

positive $R_{\text {eco }}$ effect sizes of dry versus wet peatlands; $72.2 \pm 110$ (SD) $\mathrm{mg} \mathrm{m}^{-2} \mathrm{~h}^{-1}[61]$ and $269 \mathrm{mg} \mathrm{m}^{-2} \mathrm{~h}^{-1}$ [68].

\section{Poor-vs-rich}

Two studies classified peatlands as 'poor' or 'rich'. Poor fens are generally characterised by lower $\mathrm{pH}$ and nutrient concentrations, and 'rich' sites by higher $\mathrm{pH}$ and nutrients. The authors also note that their 'poor' sites tended to have lower water tables than their 'rich' sites [69]. Although not explicitly stated, this was interpreted as a natural contrast between sites, rather than an effect of management. In the two studies, which were undertaken at the same sites, $\mathrm{CH}_{4}$ was found to be produced at higher rates in richer peats [69], DOC concentration to be higher in poorer peats $[69,70]$,

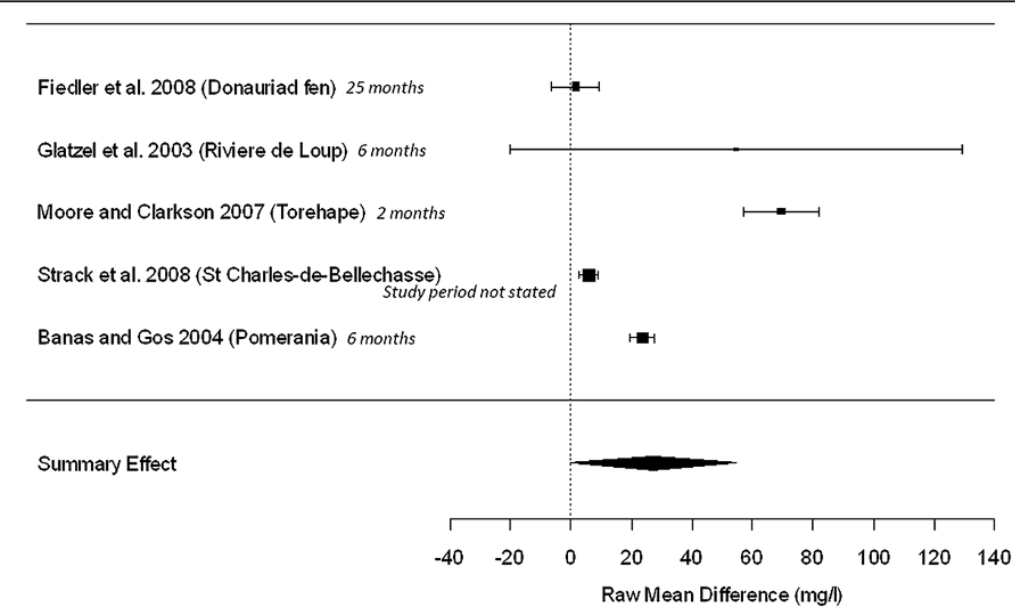

Figure 10 Forest plot of meta-analysis of effect sizes (raw mean difference) comparing dissolved organic carbon (DOC) concentration in drained versus undrained peatlands. The dashed line represents no effect. Size of boxes represents the weight of the study in the analysis. Horizontal lines represent 95\% confidence intervals. Positive effect sizes indicate greater concentration in drained peatlands than undrained controls. The position of the centre of the diamond represents the overall summary effect (a weighted average) and its horizontal extent represents the positive and negative $95 \%$ confidence intervals. 


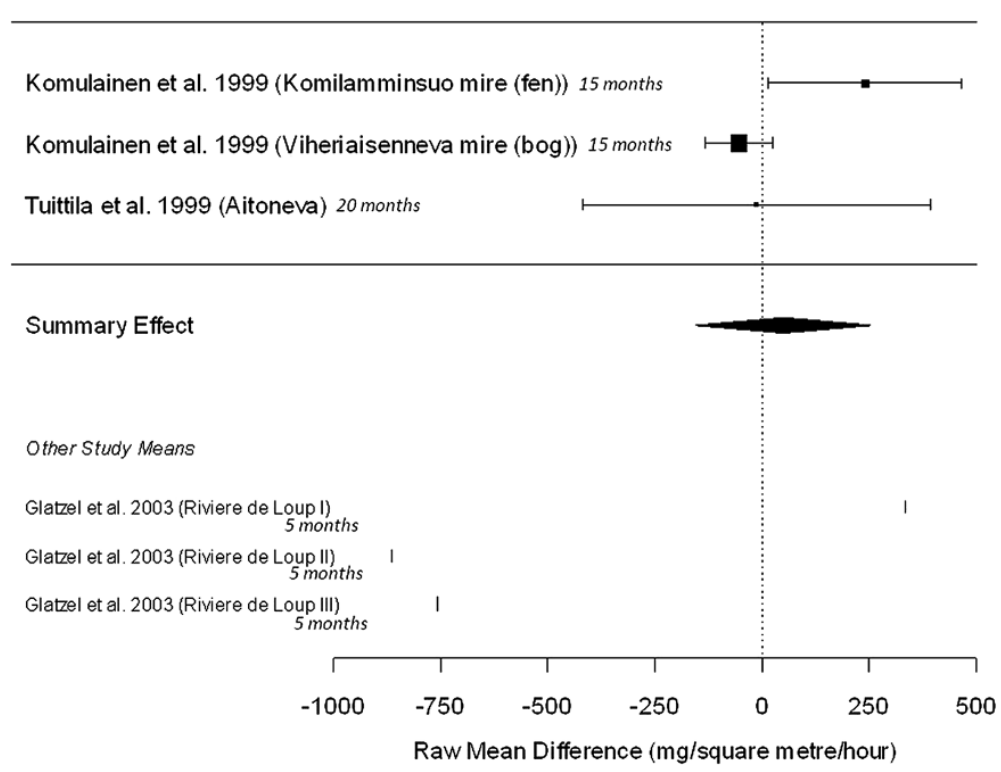

Figure 11 Forest plot of meta-analysis of effect sizes (raw mean difference) comparing total ecosystem respiration $\left(R_{\text {eco }}\right)$ in restored versus unrestored peatlands. The dashed line represents no effect. Size of boxes represents the weight of the study in the analysis. Horizontal lines represent $95 \%$ confidence intervals. Positive effect sizes indicate greater flux in restored peatlands than unrestored peatlands. The position of the centre of the diamond represents the overall summary effect (a weighted average) and its horizontal extent represents the positive and negative 95\% confidence intervals. Other Study Means are provided for studies where a measure of variability could not be extracted.

and ecosystem respiration rate to be higher in poorer peats [69] (see narrative synthesis tables in Additional file 10). These results are consistent with the comparison of drained vs undrained sites, and thus with water table providing the primary control on emissions and fluxes from these sites.

\section{Irrigated-vs-non-irrigated}

One study [71] compared emission and soil surface concentration of $\mathrm{N}_{2} \mathrm{O}$ from rain-fed peat soils with nonirrigated peat soils. $\mathrm{N}_{2} \mathrm{O}$ emission was higher in nonirrigated soils, whilst the opposite was true for soil

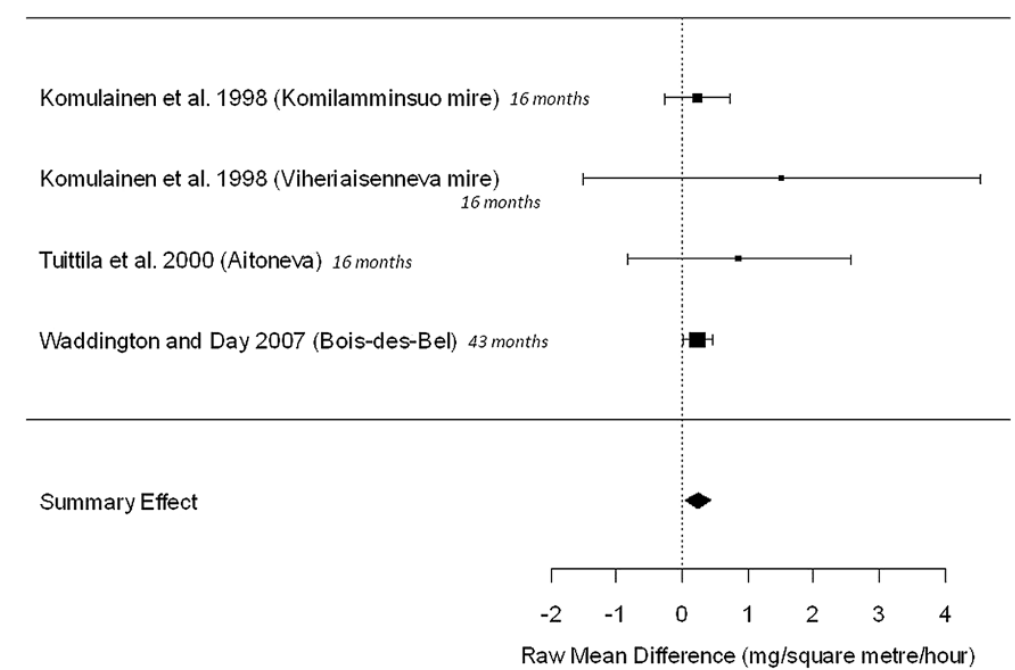

Figure 12 Forest plot of meta-analysis of effect sizes (raw mean difference) comparing $\mathrm{CH}_{4}$ flux from restored versus unrestored peatlands. The dashed line represents no effect. Size of boxes represents the weight of the study in the analysis. Horizontal lines represent $95 \%$ confidence intervals. Positive effect sizes indicate greater flux in restored peatlands than unrestored peatlands. The position of the centre of the diamond represents the overall summary effect (a weighted average) and its horizontal extent represents the positive and negative 95\% confidence intervals. 


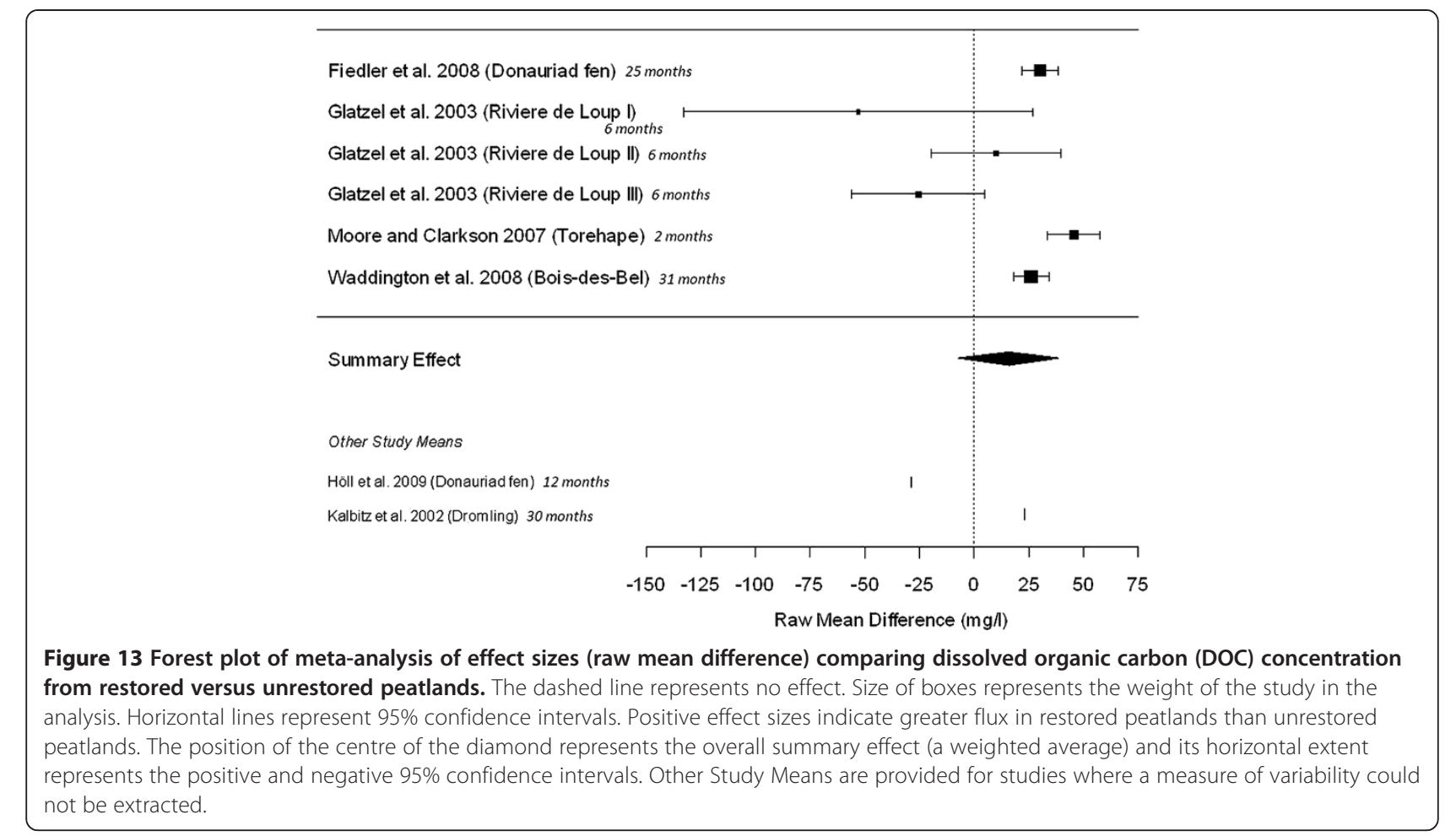

surface $\mathrm{N}_{2} \mathrm{O}$ concentration (see narrative synthesis tables in Additional file 10).

\section{Farmland interventions}

\section{High intensity farmed-vs-low intensity farmed}

A total of nine studies report seven different measured outcomes, but only two of these outcomes $\left(\mathrm{CH}_{4}\right.$ and $\mathrm{N}_{2} \mathrm{O}$ ) had sufficient studies to allow meta-analysis.
$\mathrm{CH}_{4}$ Farming intensity had no significant effect on $\mathrm{CH}_{4}$ emission across the four included studies (Table 7 and Figure 15). Whilst no heterogeneity was found across studies, the studies by Petersen et al. [40] showed much higher variability than the other two studies, possibly because they used nationwide survey data rather than site-based experimental comparisons. The Petersen et al. [40] studies were classed as 'unclear' in their susceptibility to bias, and more information on the methodology

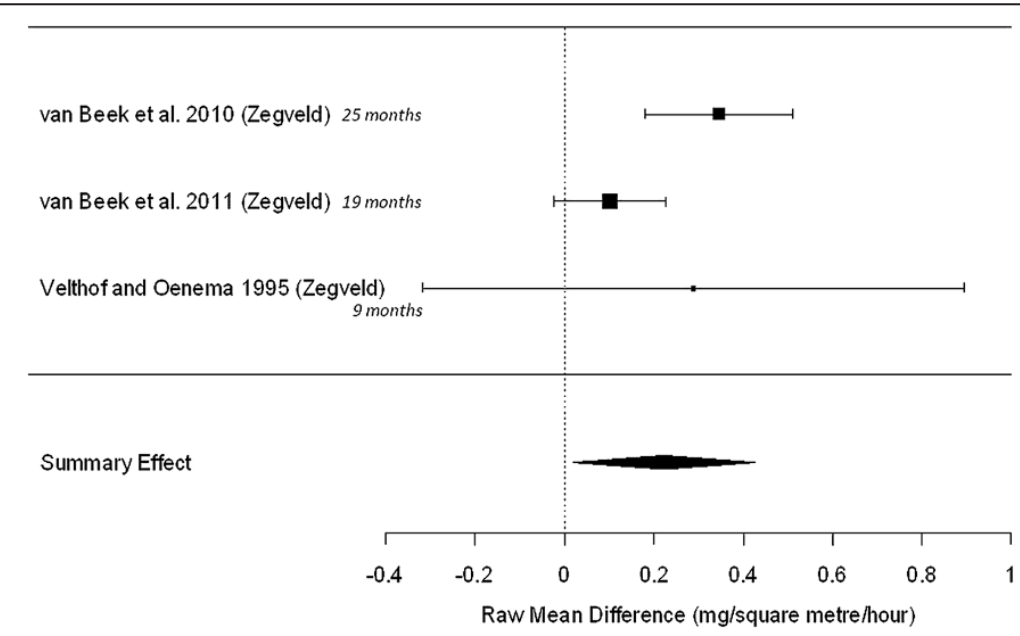

Figure 14 Forest plot of meta-analysis of effect sizes (raw mean difference) comparing $\mathrm{N}_{2} \mathrm{O}$ flux from wet versus dry peatlands. The dashed line represents no effect. Size of boxes represents the weight of the study in the analysis. Horizontal lines represent $95 \%$ confidence intervals. Positive effect sizes indicate greater flux in wet peatlands than dry peatlands. The position of the centre of the diamond represents the overall summary effect (a weighted average) and its horizontal extent represents the positive and negative $95 \%$ confidence intervals. 
involved would be needed before the low precision can be accounted for.

$\mathrm{N}_{2} \mathrm{O}$ Farming intensity was not found to have a significant effect on $\mathrm{N}_{2} \mathrm{O}$ emission across the included studies (Table 7 and Figure 16). Significant heterogeneity was identified, however. Only two of the five included studies cross the line of no effect, indicating that in individual locations there may be an effect of farming intensity on $\mathrm{N}_{2} \mathrm{O}$ emission and suggesting that further studies would be particularly valuable.

Other measured outcomes Five other outcomes were reported across seven studies (see narrative synthesis tables in Additional file 10); namely, C store, DOC concentration, long-term subsidence, SOC concentration and $R_{\text {eco }}$. The various different measures of $C$ concentration showed a range of results; both positive and negative with respect to farming impact. $R_{\text {eco }}$ showed varied results with effect sizes from -251 to $93.6 \mathrm{mg} \mathrm{m}^{-2} \mathrm{~h}^{-1}$ (high intensity relative to low intensity farming).

Cropped-vs-bare Three studies reported $\mathrm{CH}_{4}$ emission on cropped versus bare peat (i.e. actively extracted) (see narrative synthesis tables in Additional file 10 for details). Two studies reported negative effect sizes [72, $-0.070 \pm 0.053$ (SD)], [73, -0.003] and one a positive effect size [74, $0.007 \pm 0.008$ (SD)]. Two studies measured $R_{\text {eco }}$ for cropped and bare peats $[73,74]$, finding conflicting positive $\left(48.8 \mathrm{mg} \mathrm{m}^{-2} \mathrm{~h}^{-1}\right)$ and negative $\left(-11.4 \pm 8.75\right.$ (SD) $\left.\mathrm{mg} \mathrm{m}^{-2} \mathrm{~h}^{-1}\right)$ effect sizes respectively.

Fertilised-vs-less fertilised Ten studies contributed 14 lines of data across four different outcomes for peatlands with experimental gradients in fertilisation rate (see narrative synthesis tables in Additional file 10). For $\mathrm{CH}_{4}$ emission effect sizes were negative $(-2.58 \pm 1.61$ (SD) $\mathrm{mg}$ $\mathrm{m}^{-2} \mathrm{~h}^{-1}$, and $\left.-0.117 \mathrm{mg} \mathrm{m}^{-2} \mathrm{~h}^{-1}\right)$ or zero $(0.000 \pm 0.005$ (SD) $\mathrm{mg} \mathrm{m}^{-2} \mathrm{~h}^{-1}$ ) indicating greater or negligible emission in controls than intervention soils. For $\mathrm{N}_{2} \mathrm{O}$ emission effect sizes were predominantly positive (six values ranging from 0.004 to $17.0 \mathrm{mg} \mathrm{m}^{-2} \mathrm{~h}^{-1}$ ) with one negative value $\left(-0.092 \pm 0.103(\mathrm{SD}) \mathrm{mg} \mathrm{m}^{-2} \mathrm{~h}^{-1}\right)$, with positive values signifying greater emission on fertilised soils and vice versa. The two studies reporting NEE showed very different outcomes, with effect sizes of $214 \pm 459$ (SD) $\mathrm{mg} \mathrm{m}^{-2} \mathrm{~h}^{-1}$ and $-272 \pm 70.3$ (SD) $\mathrm{mg} \mathrm{m}^{-2} \mathrm{~h}^{-1}$. Similarly, the three measured total respiration $\left(\mathrm{CO}_{2}\right)$ effect sizes ranged from -16.1 to $601 \pm 522$ (SD) $\mathrm{mg} \mathrm{m}^{-2} \mathrm{~h}^{-1}$ indicating a substantial degree of variability amongst studies.

Grazed-vs-mown Four studies compared grazed and mown peatland fields. Three of these reported $\mathrm{CH}_{4}$ emissions and are analysed below, whilst only one measured $\mathrm{N}_{2} \mathrm{O}$ emissions.

$\mathrm{CH}_{4}$ No significant difference in $\mathrm{CH}_{4}$ emissions was identified between grazed and mown peat soils (Table 7 and Figure 17). However, significant heterogeneity was identified, highlighting the very small variability reported in the van den Pol-van Dasselaar et al. [66] study.

Other measured outcomes One study reported $\mathrm{N}_{2} \mathrm{O}$ emission in grazed and mown peats, finding greater emission on grazed soils $\left[65,0.256 \pm 0.220(\mathrm{SD}) \mathrm{mg} \mathrm{m}^{-2} \mathrm{~h}^{-1}\right]$.

Fertilised and grazed-vs-unfertilised and mown One study compared fertilised grazed peatland with unfertilised

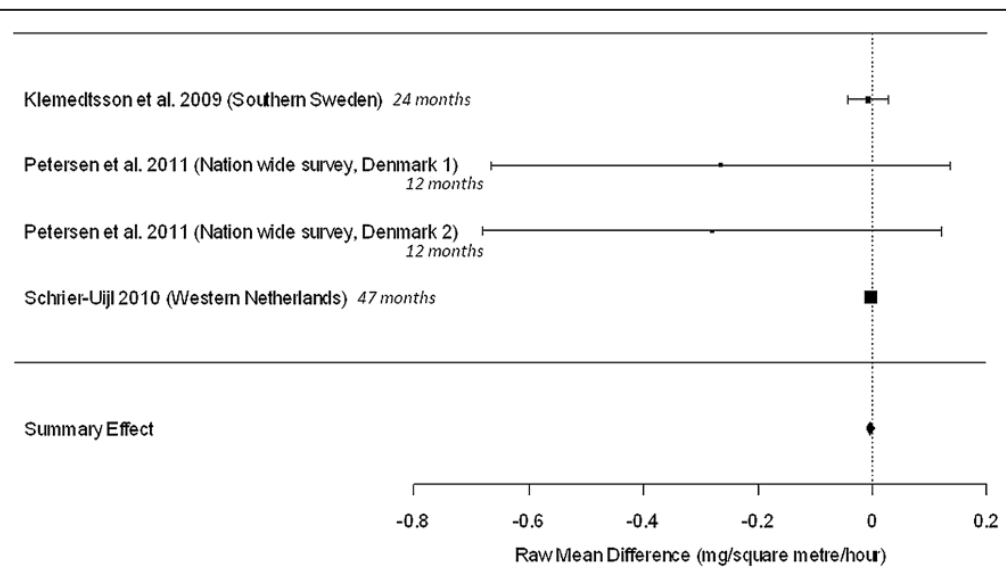

Figure 15 Forest plot of meta-analysis of effect sizes (raw mean difference) comparing $\mathrm{CH}_{4}$ flux from high intensity versus low intensity farmed peatlands (see text for definition). The dashed line represents no effect. Size of boxes represents the weight of the study in the analysis. Horizontal lines represent $95 \%$ confidence intervals. Positive effect sizes indicate greater flux in high-intensity farmed peatlands than in low-intensity. The position of the centre of the diamond represents the overall summary effect (a weighted average) and its horizontal extent represents the positive and negative $95 \%$ confidence intervals. 


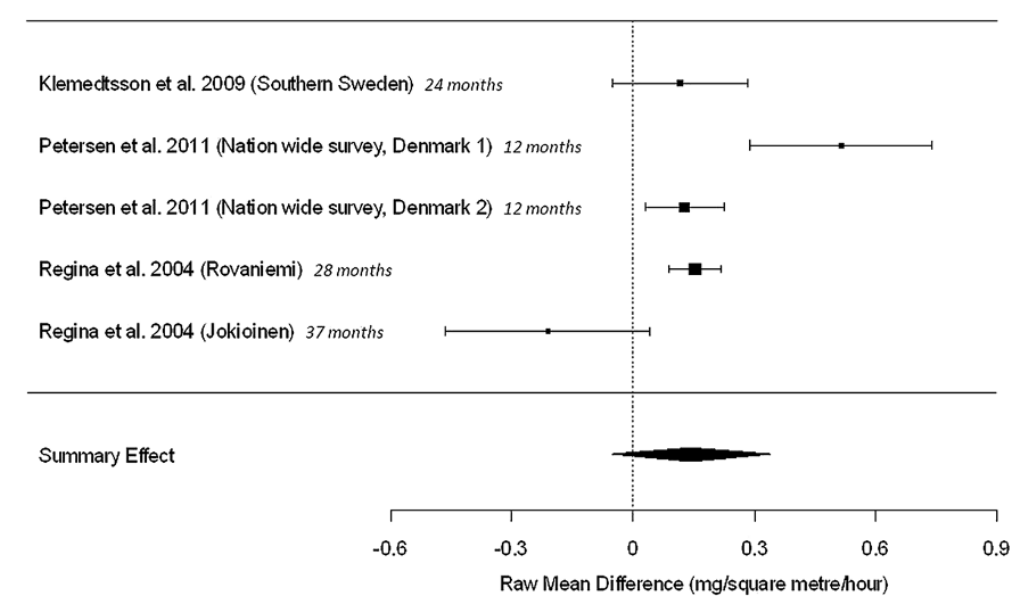

Figure 16 Forest plot of meta-analysis of effect sizes (raw mean difference) comparing $\mathrm{N}_{2} \mathrm{O}$ flux from high intensity versus low intensity farmed peatlands (see text for definition). The dashed line represents no effect. Size of boxes represents the weight of the study in the analysis. Horizontal lines represent 95\% confidence intervals. Positive effect sizes indicate greater flux in high-intensity farmed peatlands than low-intensity. The position of the centre of the diamond represents the overall summary effect (a weighted average) and its horizontal extent represents the positive and negative $95 \%$ confidence intervals.

mown peatland. The confounding nature of these two interventions prevented their collation with studies in Sections Fertilised-vs-less fertilised and Grazed-vs-mown. This study showed that $\mathrm{N}_{2} \mathrm{O}$ emissions were greater under the fertilized grazed regime by $0.260 \pm 0.311$ (SD) $\mathrm{mg} \mathrm{m}^{-2} \mathrm{~h}^{-1}$ [64].

\section{Other interventions}

\section{Grass-vs-forest}

One study measured $\mathrm{CH}_{4}$ emission, $\mathrm{N}_{2} \mathrm{O}$ emission, soil air $\mathrm{N}_{2} \mathrm{O}$ concentration, and total respiration
$\left(\mathrm{CO}_{2}\right)$ flux in a grass peatland field versus a forested peatland field [39]. All measured GHG emissions/ concentrations were greater on the grass field than the forested field (see narrative synthesis tables in Additional file 10).

Old abandoned-vs-recently abandoned One study examined the impact of time since abandonment on $R_{\text {eco }}$ [75], finding a positive effect size but not reporting a measure of variability (see narrative synthesis tables in Additional file 10).

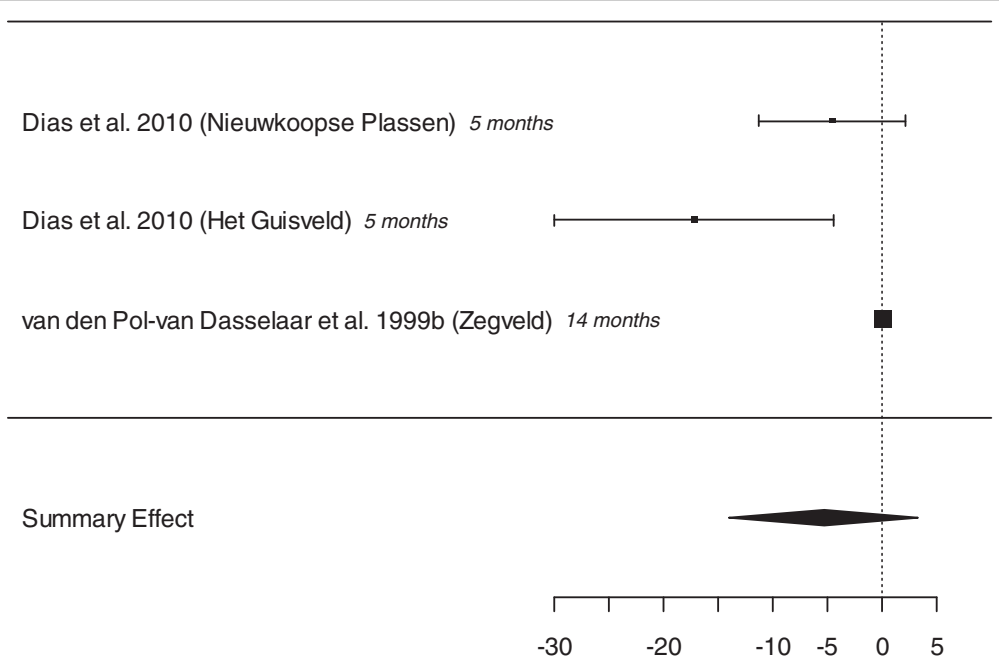

Raw Mean Difference (mg/square metre/hour)

Figure 17 Forest plot of meta-analysis of effect sizes (raw mean difference) comparing $\mathrm{CH}_{4}$ flux from grazed versus mown peatlands. The dashed line represents no effect. Size of boxes represents the weight of the study in the analysis. Horizontal lines represent $95 \%$ confidence intervals. Positive effect sizes indicate greater flux in grazed peatlands than mown peatlands. The position of the centre of the diamond represents the overall summary effect (a weighted average) and its horizontal extent represents the positive and negative 95\% confidence intervals. 
Recently-vs-long-term afforested One study reported $\mathrm{CH}_{4}, \mathrm{~N}_{2} \mathrm{O}$ and $\mathrm{R}_{\text {eco }}$ emissions for peatlands afforested two years prior to study versus 24 years previous [38]. Both $\mathrm{CH}_{4}$ and $\mathrm{R}_{\text {eco }}$ emissions were greater on more recently afforested peatlands $(-0.410 \pm 0.634$ and -125 $\pm 90.2 \mathrm{mg} \mathrm{m}^{-2} \mathrm{~h}^{-1}$ respectively), whilst $\mathrm{N}_{2} \mathrm{O}$ emission was greater in older forests by $0.072 \pm 0.197$ (SD) $\mathrm{mg} \mathrm{m}^{-2} \mathrm{~h}^{-1}$ [38].

Mineral soil dressed-vs-undressed drained peat Only one study measured the impact of mineral soil-dressing on drained peatland, finding $\mathrm{N}_{2} \mathrm{O}$ to be released at a greater rate from the undressed peat $[76,-0.111 \pm 0.247$ (SD)].

Combined 'drier-vs-wetter' peat (drained-vs-undrained, dry-vs-wet, and unrestored-vs-restored) Three intervention/exposure categories (drained-vs-undrained, dry-vs-wet, and unrestored-vs-restored) were combined for $\mathrm{CH}_{4}$ and $\mathrm{R}_{\text {eco }}$ into one category ('drier-vs-wetter') since this allowed the addition of one extra study in each case that was excluded from the above meta-analyses as it was a single study within its intervention/exposure group. In this larger group, restored-vs-unrestored has been reversed to reflect the same direction of effect relative to 'drier versus wetter' peatlands.

Ecosystem respiration $\left(\boldsymbol{R}_{\text {eco }}\right)$ Drier peat soils released, on average, $88.8 \mathrm{mg} \mathrm{m}^{-2} \mathrm{~h}^{-1}$ (95\% $\mathrm{CI}=-7.97$ to 186 ) more $\mathrm{CO}_{2}$ through respiration than wetter peats, although this result is only marginally significant $(\mathrm{p}=0.072)$ (Figure 18). There is significant heterogeneity across studies $\left(\mathrm{QE}_{13}=158\right.$ $\mathrm{p}<0.001)$, as found with the individual group analyses. This was investigated using meta-regression, including mean site air temperature $\left(\mathrm{T}_{\text {air }}\right)$ and mean precipitation (PPT) reported for each site or taken from 30 year mean data within other articles. These analyses showed that neither mean air temperature nor mean precipitation were significantly responsible for the heterogeneity observed ( $\mathrm{T}_{\text {air }} ; \mathrm{QM}_{1}=0.002 \mathrm{p}=0.968$. PPT; $\mathrm{QM}_{1}=0.271$ $\mathrm{p}=0.602)$.

$\mathrm{CH}_{4}$ Drier peats released, on average, $-0.131 \mathrm{mg} \mathrm{m}^{-2} \mathrm{~h}^{-1}$ (95\% $\mathrm{CI}=-2.54$ to -0.009$)$ more $\mathrm{CH}_{4}$ than wetter peat soils $(\mathrm{p}=0.035)$ (Figure 19). Combining these three categories produces a significant effect size of lower $\mathrm{CH}_{4}$ emissions from the drier peatland, whereas the reduction in emission in drained-vs-undrained alone was marginal $(\mathrm{p}=0.055$, Table 7 and Figure 8), although unrestored peatland did show significantly lower emissions than restored. The study by van den Pol-van Dasselaar et al. [66] of naturally dry versus wet peatland is strongly weighted in this combined analysis, but it possesses a small effect size.

\section{Discussion}

\section{Major findings}

The evidence base concerning the impact of land management activities on GHG flux and C stores in lowland peatlands is rather limited in extent. Furthermore, the disparate nature of the different management drivers studied, variables measured and ways in which the results are reported makes quantitative synthesis difficult or in some cases impossible. Some interventions/exposures are better covered (e.g. drainage) than others (e.g. restoration). This may reflect the fact that restoration through rewetting is a fairly recent intervention [77] and that long-term studies are lacking relative to those on earlier drainage [25]. However, whilst the scopes and designs of included studies vary considerably, our review has highlighted a number of significant patterns across the evidence base (see Table 9).

Firstly, less $\mathrm{CH}_{4}$ is emitted by drained lowland peatlands than from undrained peats. Secondly, more $\mathrm{CH}_{4}$ is emitted by restored (i.e. rewetted) lowland peatlands than those that have been similarly previously drained but not restored. The finding that wetter peat soils produce more $\mathrm{CH}_{4}$ is in accordance with the concept that $\mathrm{CH}_{4}$ emission increases, as higher water tables increase anaerobic decomposition of soil organic matter $[78,79]$. Similar findings were reported in the global review of all peatlands by Bussell et al. [25]. Our review found 0.126 $\mathrm{mg} \mathrm{m}^{-2} \mathrm{~h}^{-1}$ (95\% CI $=0.003$ to $0.254 ; 9$ studies) more $\mathrm{CH}_{4}$ released from undrained than drained peats, whilst Bussell et al. [25] reported a figure of $0.335 \mathrm{mg} \mathrm{m}^{-2} \mathrm{~h}^{-1}$ (95\% CI $=0.200$ to $0.467 ; 27$ studies). Our review found $0.248 \mathrm{mg} \mathrm{CH}_{4} \mathrm{~m}^{-2} \mathrm{~h}^{-1}$ (95\% $\mathrm{CI}=0.052$ to $0.446 ; 4$ studies) more $\mathrm{CH}_{4}$ released from restored than unrestored peats, whilst Bussell et al. [25] reported a figure of $0.667 \mathrm{mg}$ $\mathrm{m}^{-2} \mathrm{~h}^{-1}$ (95\% CI $=0.017$ to $1.32 ; 5$ studies). Upland (blanket bog) peatlands accounted for a high proportion of the studies reviewed by Bussell et al. [25]. Although the comparison of the two reviews may indicate that the impacts of re-wetting drained peatlands, in terms of greater $\mathrm{CH}_{4}$ emission, may be less in the lowlands than the uplands, this observed difference is based on a relatively few studies and may arise by chance.

Thirdly, more $\mathrm{N}_{2} \mathrm{O}$ is emitted by drained lowland peatlands and dry peatlands than their undrained and wet counterparts. Emission of $\mathrm{N}_{2} \mathrm{O}$ may increase as aerobic conditions that extend to greater depths in drained peats favour nitrification [80], whilst in undisturbed wetter peat soils the anaerobic conditions of elevated water tables may limit $\mathrm{N}_{2} \mathrm{O}$ production. A similar finding was reported in the review of all peatlands by Bussell et al. [25], with drained peatlands producing on average 3.97 $\mu \mathrm{g} \mathrm{m} \mathrm{m}^{-2} \mathrm{~h}^{-1}$ more $\mathrm{N}_{2} \mathrm{O}$ than undrained peats $(95 \%$ $\mathrm{CI}=2.63$ to 5.33 ; 13 studies), compared with our finding for lowland peatlands of a much larger effect size of 8.28 


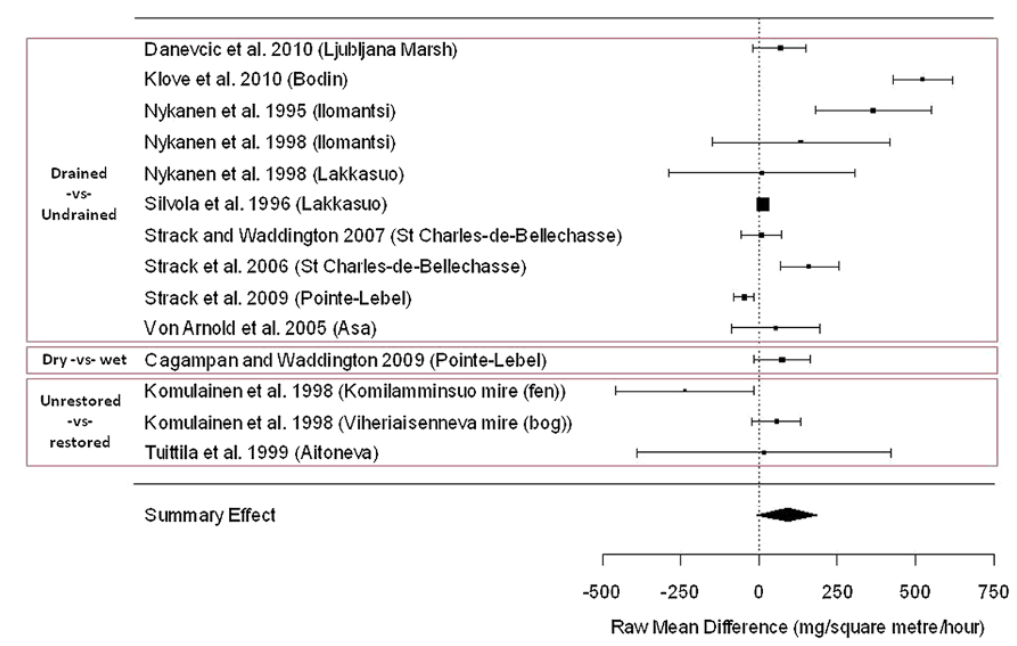

Figure 18 Forest plot of meta-analysis of effect sizes (raw mean difference) comparing total ecosystem respiration ( $\left.R_{\text {eco }}\right)$ in 'drier versus wetter' peatlands. The dashed line represents no effect. Size of boxes represents the weight of the study in the analysis. Horizontal lines represent 95\% confidence intervals. Positive effect sizes indicate greater flux in drier peatlands than wetter counterparts. The position of the centre of the diamond represents the overall summary effect (a weighted average) and its horizontal extent represents the positive and negative $95 \%$ confidence intervals. Red boxes indicate where the original grouping of intervention/exposure categories lies.

$\mu \mathrm{g} \mathrm{m} \mathrm{m}^{-2} \mathrm{~h}^{-1}$ (95\% $\mathrm{CI}=0.659$ to $15.9 ; 5$ studies). A greater $\mathrm{N}_{2} \mathrm{O}$ response in lowland peats may reflect their typically higher nutrient levels, either naturally (in fens) or as a consequence of management (e.g. associated with fertilisation or higher livestock densities). Alternatively, this difference may reflect chance variability between the studies included in the respective reviews.

Finally, more $\mathrm{CO}_{2}$ was produced through respiration by drained lowland peatlands than undrained peats. This finding can be related to the rapid release of $\mathrm{CO}_{2}$ that results from aerobic microbial respiration as the peat profile moves away from the anoxic conditions of undrained peat. The review of all global peatlands by Bussell et al. [25] reported the same direction of effect, but a nonsignificant, lower value; with drained peats respiring 59.8 $\mathrm{mg} \mathrm{m}^{-2} \mathrm{~h}^{-1}$ more $\mathrm{CO}_{2}$ than undrained peats $(95 \% \mathrm{CI}=16.7$ to $100 ; 21$ studies), compared with our finding of $125 \mathrm{mg}$ $\mathrm{CO}_{2} \mathrm{~m}^{-2} \mathrm{~h}^{-1}$ (95\% $\mathrm{CI}=6.71$ to $243 ; 10$ studies).

\section{Reasons for heterogeneity}

Given the low number of primary studies investigating lowland-type peatlands which met the criteria for inclusion in the systematic review, few opportunities for investigation of sources of heterogeneity were available. As

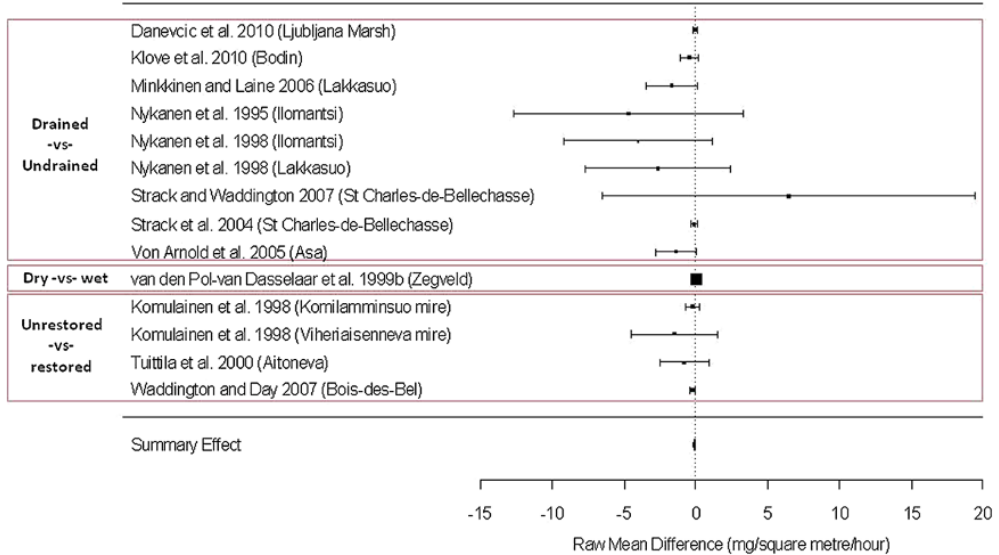

Figure 19 Forest plot of meta-analysis of effect sizes (raw mean difference) comparing $\mathrm{CH}_{4}$ flux from 'drier versus wetter' peatlands. The dashed line represents no effect. Size of boxes represents the weight of the study in the analysis. Horizontal lines represent $95 \%$ confidence intervals. Positive effect sizes indicate greater flux in drier peatlands than wetter counterparts. The position of the centre of the diamond represents the overall summary effect (a weighted average) and its horizontal extent represents the positive and negative 95\% confidence intervals. Red boxes indicate where the original grouping of intervention/exposure categories lies. 
Table 9 Major findings from the quantitative synthesis of the evidence-base

\begin{tabular}{|c|c|c|c|c|c|}
\hline Intervention/exposure-vs-comparator & $\mathrm{CH}_{4}$ & DOC & $\mathrm{N}_{2} \mathrm{O}$ & $\mathrm{NEE} \mathrm{CO}{ }_{2}$ & $\mathrm{R}_{\mathrm{eco}} \mathrm{CO}_{2}$ \\
\hline \multirow[t]{3}{*}{ Drained-vs-undrained } & $S E E=-0.126$ & $\mathrm{SEE}=27.3$ & $\mathrm{SEE}=0.008$ & & $\mathrm{SEE}=125$ \\
\hline & $\mathrm{p}=0.055$ (.) & $p=0.051$ (.) & $\mathrm{p}=0.033\left(^{*}\right)$ & n.s. & $\mathrm{p}=0.038\left(^{*}\right)$ \\
\hline & $\mathrm{n}=9$ & $\mathrm{n}=5$ & $\mathrm{n}=5$ & $n=3$ & $n=10$ \\
\hline \multirow[t]{3}{*}{ Dry-vs-wet } & & & $\mathrm{SEE}=0.221$ & & \\
\hline & & & $\mathrm{p}=0.019\left(^{*}\right)$ & & \\
\hline & & & $n=3$ & & \\
\hline \multirow[t]{2}{*}{ Grazed-vs-mown } & n.s. & & & & \\
\hline & $n=3$ & & & & \\
\hline \multirow[t]{3}{*}{ Restored-vs-unrestored } & $\mathrm{SEE}=0.248$ & & & & \\
\hline & $\mathrm{p}=0.014\left(^{*}\right)$ & n.s. & & & n.s. \\
\hline & $n=4$ & $\mathrm{n}=8$ & & & $n=3$ \\
\hline \multirow[t]{2}{*}{ High intensity farmed-vs-low intensity farmed } & n.s. & & n.s. & & \\
\hline & $n=5$ & & $n=6$ & & \\
\hline
\end{tabular}

SEE, summary effect estimate; n.s., non-significant; $p, p$-value; $n$, number of studies; $\left({ }^{*}\right)$, significant; (.), marginally significant ( $\left.\alpha=0.05\right)$.

future research is integrated into these meta-analyses, other sources of heterogeneity, such as soil type, climate, and susceptibility to bias judgements should be included in meta-regression and subgroup analysis.

It should be added that the amalgamation of studies within an intervention adds heterogeneity, since studies will differ in the intensity of their intervention and form of the comparator. This will increase the variability in the summary effect estimate. However, this will make the results herein more conservative, since the variability around the summary effect will be larger than for a meta-analysis of studies with identical intervention and comparator pairs.

\section{Strengths and limitations of the review}

This review is the first collation and synthesis of the literature on lowland peat C balances and GHG flux. As a systematic review it has included all of the available evidence on the subject and has objectively and transparently assessed the relevance and validity of all included studies. The review results, however, are more limited than similar findings for upland peats (or peats in general) because of the relative scarcity of research in lowland peatland environments. Many of the studies that did meet the criteria for inclusion were obtained from boreal 'mire' systems in Scandinavia and Canada. These systems could potentially differ considerably from the smaller, temperate lowland raised bog and fen systems of other regions, such as the UK. As research on lowland peats in other regions continues, the relevance of updates to this review's conclusions to areas outside the currently more studied regions will increase. Despite these limitations, this review has taken a first step in compiling and synthesising the results of the available literature, and will act as a strong foundation for future updates of the review as further research on lowland peats becomes available.

Of the 282 articles identified as potentially relevant from abstract-level assessment and other sources of relevant literature, 79 could not be obtained due to restrictions on access or inability to identify the holding institutions. At 28 percent, this is rather a high proportion of unobtainable texts. Many of these articles were published in non-English language journals and the titles provided by the listing literature database may be English translations of their published counterparts, which is a possible reason we have been unable to locate them. This number is likely to be an overestimate of the relevance of the full texts, since those articles that lacked an abstract were included out of caution. Since primary literature accessibility is continually improving, future updates to this review will be able to lower the proportion of unobtainable articles as more research is published.

We have not combined those studies with multiple outcomes in a multivariate meta-analysis, since the separate outcomes can be viewed as independent of one another. For the same reason we have chosen not to correct our p-values across different outcomes for the same studies for multiplicity, which itself is a subject of controversy [81].

\section{Limitations of the evidence base}

The number of studies investigating the impacts of land management on GHG fluxes and C stores in lowland peatlands is rather low. This was also noted in the review of drainage and rewetting on GHG and C stores in peatlands worldwide [25]. In addition, studies often failed to report measures of variability within their results; also a finding of Bussell et al. [25]. Means alone cannot be included in meta-analysis, and a substantial 
proportion of the data from the literature could not be quantitatively synthesised as a result. Due to the lack of studies focusing on lowland peatlands in general and the lack of reporting of variability measures, the metaregressions and subgroup analyses undertaken by Bussell et al. [25] in their review of global peatlands could not be undertaken in this review. Further investigation of the factors that may contribute to the heterogeneity seen across some of the evidence (for example total ecosystem respiration responses to drainage) will become possible as more evidence is made available in future years, and regular updates to this review are vital to capture this important information.

The included studies employed a range of different study periods, from 1 month to 60 . Shorter studies may identify different net changes in outcome measures relative to longer studies: interventions or exposures may have very different short term consequences relative to the longer term. There were insufficient studies in our meta-analyses to allow study period to be included as a covariate. Future updates to this review may be able to examine the influence of study length on heterogeneity amongst studies.

It is surprising that very few studies focused on changes to $\mathrm{C}$ stores relative to GHG fluxes. Changes in organic $\mathrm{C}$ content of peatlands can, theoretically, occur without the release of GHGs, for example through DOC export, which has been found to be significant in some studies e.g. [82]. While $\mathrm{C}$ stock changes are difficult to measure directly, since changes are small relative to the total pool size, methods based on peat subsidence have been successfully applied in other regions, notably in tropical peatlands e.g. [83]. Similarly, few (9) studies examined $\mathrm{CO}_{2}$ sequestration either through plant $\mathrm{CO}_{2}$ photosynthesis (gross primary production) or through whole ecosystem net $\mathrm{CO}_{2}$ exchange (NEE) relative to the number of studies that examined $\mathrm{CO}_{2}$ respiration $\left(\mathrm{R}_{\text {eco }}\right)$ alone (37 studies). The inclusion of measurement of fluxes of all GHG gases and all forms of $\mathrm{C}$ store would allow a more thorough investigation of the impact of land management on peatlands, and future studies should include such $\mathrm{C}$ measurements. Where the hydrological regime permits, measurement of fluxes in DOC and POC would provide a valuable addition to the completeness of the picture of ecosystem $\mathrm{C}$ cycling.

Furthermore, as elaborated upon below, studies often reported temporal variability in measurements as a proxy for spatial replication, or combined spatial and temporal replication together in their presentation of results. Primary research is often not designed with forethought of metaanalysis, and the reporting of temporal variability is perfectly acceptable. However it should not be treated as providing replication that is comparable in rigour to that achieved through true spatial replication. In some instances the statistics undertaken within the primary research papers were incorrect through the use of temporal replication instead of spatial (true) replication.

\section{Review conclusions}

\section{Implication for policy/management}

The results of this review provide some empirical underpinning for policy on the management of lowland peatlands in relation to GHG emissions. The data show a consistent pattern of lower $\mathrm{CH}_{4}$ emissions from drained sites, and that this is reversed by re-wetting over the short to medium term (12 to 32 months). These results are consistent with previous findings e.g. [19], although they do not take account of potential modifying factors, such as the role of drainage ditches as a $\mathrm{CH}_{4}$ source in drained peatlands [24] or the influence of different vegetation types on emissions from re-wetted sites. For $\mathrm{N}_{2} \mathrm{O}$, the significant pattern of increased emissions from drained sites is also consistent with previous assessments e.g. [14,25]. It is interesting to note that, in terms of 100 year Global Warming Potential, the average increase in $\mathrm{N}_{2} \mathrm{O}$ emissions following drainage approximately equates to the decrease in $\mathrm{CH}_{4}$, suggesting a small net effect. However, this is unlikely to hold true on an individual site basis, since the emissions of both GHGs will potentially be affected by a range of site factors. For example, the review showed a general tendency towards higher $\mathrm{N}_{2} \mathrm{O}$ emissions from intensively farmed or fertilised sites, but neither effect was statistically significant given the small number of available studies. Management factors are therefore likely to be influential in moderating the effects of lowland peat management on GHG fluxes, but additional primary data are required to quantify these effects.

For $\mathrm{CO}_{2}$, the scarcity of comprehensive, replicated experimental studies makes it surprisingly difficult to draw clear conclusions about the effects of peatland management on the overall $\mathrm{C}$ balance. The number of studies measuring NEE was insufficient to draw clear conclusions, and similarly there were insufficient studies to elucidate the effects of other land-management activities on $\mathrm{CO}_{2}$ fluxes. While peat subsidence records e.g. [84] and individual flux measurement studies e.g. [85] in drained agricultural lowland peats strongly indicate that they are large net $\mathrm{CO}_{2}$ sources, there remains a lack of rigorous experimental data from which to derive robust effect sizes, or emissions factors, as a function of management. For DOC, again based on limited data, there appears to be a tendency towards higher DOC concentrations from drained lowland peats, but this effect was not significant based on the currently available studies. Re-wetting studies do not currently demonstrate a corresponding DOC reduction following the raising of water tables, perhaps due to the confounding effects of time since restoration and the short duration of many studies. 
In summary, the results of the systematic review are broadly consistent, or at least do not generally conflict, with current understanding that lowland peat drainage is likely to lead to greater $\mathrm{C}$ loss (as $\mathrm{CO}_{2}$ and/or DOC), increased $\mathrm{N}_{2} \mathrm{O}$ emissions, and reduced $\mathrm{CH}_{4}$ emissions, and that these responses may, to varying degrees, be reversed by re-wetting and restoration. However, only in the case of $\mathrm{CH}_{4}$ and $\mathrm{N}_{2} \mathrm{O}$ can these inferences be clearly demonstrated by a statistical meta-analysis of current experimental studies. Furthermore, few inferences can currently be drawn from the literature regarding the size/ magnitude of effects of peatland agricultural activities including farming intensity, fertiliser use or irrigation, or of other lowland peat land-uses such as peat extraction or forestry. In consequence there is a need for additional well-designed primary measurement studies of lowland peats under a range of management regimes (see below). In the meantime, policy on lowland peat management should take account of the level of knowledge and uncertainty in the current evidence base.

\section{Implication for research Priorities for primary research}

In the UK, which formed the initial focus for this review, lowland peat ecosystems are less commonly studied than upland peatlands. In many other areas of the boreotemperate zone, where continental type bogs and fens predominate, a distinction between 'upland' and 'lowland' peats is rarely made, with most peatlands (and hence most peat-related research) falling within the latter category. Nevertheless, this systematic review has demonstrated that there are relatively few studies in the evidence base that provide robust comparisons of C and GHG fluxes in relation to management, and that more studies are required on the impacts of land management on lowland peatland systems. We have identified a range of commonly investigated land management practices and a list of commonly recorded outcome measures. These findings demonstrate the key knowledge gaps within this topic area. They also highlight areas for which some evidence currently exists but where additional data are required to strengthen current findings. Table 10 demonstrates the major gaps in the evidence-base in regards to metaanalysable groups of studies. These knowledge gaps appear to lie in the following areas: the effect of restoration on $\mathrm{N}_{2} \mathrm{O}$ emissions; the effect of fertilizer on fluxes of all GHGs, especially $\mathrm{N}_{2} \mathrm{O}$; the specific effects of ploughing/ cultivation; studies of any treatment on NEE; and the effect of farming activities on DOC.

\section{Recommended study design}

Some recommendations for the basic design of peat GHG measurement studies (including spatial scale, use of controls and pre-intervention data, replication, and duration) were previously described by Evans et al. [20]. The following highlights some specific issues affecting the use of currently published data that were highlighted by the results of this review.

Replication Pseudoreplication, where replicates are not sampled at the same level as the treatment or exposure of interest, is a major issue within the evidence base of this field. Of the 71 studies included in the synthesis, only 21 involved appropriate field- or site-level replication, and only 17 of these studies provided meta-analysable data. The remaining 49 used spatial pseudoreplication to generate measures of variability, i.e. more than one chamber per field/site. Use of pseudoreplicates as true replicates in statistical analyses is, strictly speaking, flawed. However, the limited pool of adequately replicated studies identified in this review is insufficient to permit meaningful metaanalysis, which is why we have relaxed our requirements for true replication in accordance with previous authors [25]. Pseudoreplication is only a cause for concern where authors or reviewers use the results to generalise outside the study system. In these cases independent samples must be replicated at the level at which the intervention or exposure is enacted. In experimental design, increasing replication and sample size improve the accuracy of estimated means with respect to the true population mean. With replication at the 'within-site' level the true population mean being estimated by sampling is the site mean, and the estimated mean will trend towards this value as sample size increases. When we wish to make conclusions beyond the site level, however, increasing such within-site replication (pseudoreplication) does not necessarily improve accuracy, only precision. For this reason, the external validity, or generalisability, of pseudoreplicated studies is lower than for those with true replication.

Whilst we appreciate that logistical limitations may make it difficult to maintain high levels of true (i.e. 'sitelevel') replication, pseudoreplication is not a like-for-like substitute. The only way to increase accuracy of these studies without sacrificing precision is to improve design which may require more resources/funding, since apportioning the same resources in terms of practical effort in the field across a larger number of site-level replicates will not only introduce undesirable variability (through additional moderating variables) but also stretch researchers too thinly.

More of a problem than spatial pseudoreplication is the treatment of repeated sampling, or providing true replication. This temporal pseudoreplication is not an appropriate means of estimating the variability in a comparison between spatially applied treatments or exposures. By repeatedly measuring from fixed chambers, for example, the variability we are measuring is across time, e.g. associated with variation in weather conditions or season. If we 
Table 10 Current knowledge gaps for the 16 key intervention/exposure groups for lowland peatland

\begin{tabular}{|c|c|c|c|c|c|}
\hline Intervention/exposure-vs-comparator & $\mathrm{CH}_{4}$ & $\mathrm{~N}_{2} \mathrm{O}$ & NEE $\mathrm{CO}_{2}$ & $\mathrm{R}_{\text {eco }} \mathrm{CO}_{2}$ & DOC \\
\hline Cropped-vs-bare & $2(1)$ & 1 & 0 & $1(1)$ & 0 \\
\hline Drained and restored-vs-undrained & 0 & 0 & 1 & 1 & 0 \\
\hline Drained-vs-undrained & $9(4)$ & $5(5)$ & 3 & $10(5)$ & 4 \\
\hline Dry-vs-wet & 2 & 3 & $1(1)$ & $1(1)$ & 0 \\
\hline Extracted and restored-vs-natural & 0 & 0 & 1 & 1 & 0 \\
\hline High intensity farmed-vs-low intensity farmed & 5 & 6 & 0 & $2(1)$ & 1 \\
\hline Fertilised and grazed-vs-unfertilised and mown & 0 & 1 & 0 & 0 & 0 \\
\hline Fertilised-vs-less fertilised & $2(1)$ & $2(4)$ & 2 & $2(1)$ & 0 \\
\hline Grass-vs-forest & 1 & 1 & 0 & 1 & 0 \\
\hline Grazed-vs-mown & 3 & 1 & 0 & 0 & 0 \\
\hline Irrigated-vs-non-irrigated & 0 & 1 & 0 & 0 & 0 \\
\hline Mineral soil dressed-vs-undressed peat & 0 & 1 & 0 & 0 & 0 \\
\hline Old abandoned-vs-recently abandoned & 0 & 0 & 0 & $(1)$ & 0 \\
\hline Old afforested-vs-recently afforested & 1 & 1 & 0 & 1 & 0 \\
\hline Poor-vs-rich & 1 & 0 & 0 & 1 & $2(1)$ \\
\hline Restored-vs-unrestored & 4 & (1) & 0 & $3(3)$ & 8 \\
\hline
\end{tabular}

Numbers indicate the number of studies presenting meta-analysable data for that outcome and intervention/exposure group. Bracketed numbers indicate the number of additional studies that present mean only data (i.e. no measure of variability).

wished to extrapolate forward or backwards in time and predict C stores or GHG flux, temporal replication would be appropriate. However, by confusing temporal replication with spatial replication the possibility of committing both Type I (spurious significant findings) and Type II (failure to find significance) errors is increased.

In light of these comments future research should avoid using temporal replication as a proxy for spatial replication, and should seek to increase the number of sampling sites to increase external validity.

Flux chamber equipment Many studies employed measurement-error mitigation measures as part of flux chamber equipment in order to minimise sampling impacts on measured outcomes. The reason for these efforts can be broadly summarised as attempts to maximise the signal-to-noise ratio, i.e. to reduce sampling error in an effort to increase the chance of detecting a small but significant difference between sampling populations.

Some studies used fans for this purpose, to ensure air circulation, or sealed chambers onto carefully installed collars to reduce gas emissions resulting from soil disturbance. Others used radiators to mitigate heating effects of solar radiation, or used valves to reduce suction through the soil as gas samples were extracted. Some studies were not able to use all of these elaborate equipment designs, however, because of the nature of the exposures investigated. For example, permanent collars could not be installed on actively harvested peatlands, since regular machine access was required for peat extraction. These studies used a more basic chamber lacking many of these mitigation measures that could be more readily transported and inserted into the peat.

Such differences in experimental equipment between intervention and control sites may be practically necessary, but such experimental designs are open to a number of problems. Firstly, any differences in GHG fluxes found using these different methods cannot decisively be explained by the intervention alone as they could result from differences in the reliability of the experimental apparatus. Secondly, the efforts to reduce sampling error in one site are rendered moot if other samples are not measured to the same level of precision. Thirdly, different measurement techniques such as these are highly likely to result in heterogeneous variance in the compared sample populations, requiring complex statistical analysis to compensate, and possibly reducing the rigor of the analyses used.

In order to avoid this problem, identical methods should be used on comparator and intervention/exposure sites. Where this is absolutely impossible tests should be undertaken to demonstrate that this difference in methodology does not affect the results. Surprisingly no studies identified in this review have undertaken this latter option.

Increasingly, studies are seeking to overcome the problems associated with measurements using flux chambers on a small sample area by using eddy covariance measures, which integrate fluxes over a much larger area, measure (semi-)continuously rather than periodically, and 
are not subject to some of the potential artefacts from use of chambers; although they are affected by a different set of methodological issues e.g. [20]. On the other hand, replication is difficult to achieve using eddy covariance systems given their cost and complexity, and they have therefore tended to be used singly e.g. [85] or at best on paired comparison sites. This lack of replication and comparators was a key factor limiting the use of eddy covariance data in the systematic review (e.g. Figure 4). Moving eddy covariance systems between sites provides the potential to address this problem, although the sampling issues inherent to moving towers between locations in order to obtain replication, but where the sampling is carried out over different time periods, needs to be addressed. Whilst there are increasingly sophisticated modelling methods into which GHG flux measurements can be fitted, reporting only the outputs of these and not the primary measurement results together with their quantification of variability should be avoided as it will greatly hinder the potential for future meta-analyses.

\section{Additional files}

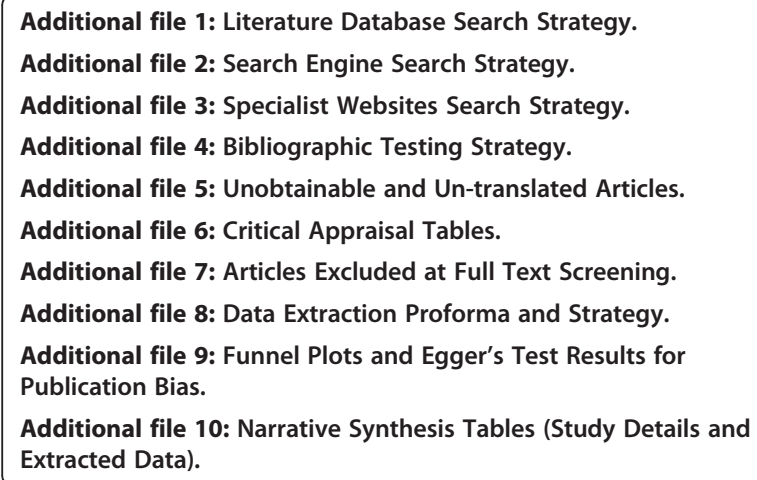

\section{Competing interests}

The authors declare that they have no competing interests.

\section{Authors' contributions}

ASP and CDE conceived and planned the review, with input from $J R H, D L$, $A B$ and SED. SED and NRH undertook the searches. $\mathrm{NRH}$ and $A B$ screened articles, with final checking by $\mathrm{CDE}$. NRH and $\mathrm{AB}$ extracted data and performed critical appraisal. NRH performed meta-analysis and carried out synthesis. $\mathrm{NRH}$ drafted the review report. $A B, C D E, J R H, D L J$ and ASP assisted in planning of and provided advice for review activities, and assisted in drafting the review report. All authors read and approved the final manuscript.

\section{Acknowledgements}

This review forms an initial stage of Defra project SP1210, to evaluate emissions and storage of $\mathrm{C}$ and GHGs. The authors wish to thank Defra for their support. We also wish to thank members of the wider research project for their comments on a draft of the manuscript.

\section{Sources of support}

This review is funded by the UK Department for Environment, Food and Rural Affairs project SP1210. The systematic review is led by CEBC with significant contributions by CEH staff, who are also responsible for the coordination of the project as a whole.

\section{Author details}

${ }^{1}$ Centre for Evidence-Based Conservation, School of Environment, Natural Resources and Geography, Bangor University, Bangor, Gwynedd LL57 2UW, UK. ${ }^{2}$ NERC Centre for Ecology and Hydrology, Bangor, UK. ${ }^{3}$ School of Environment, Natural Resources and Geography, Bangor University, Bangor, Gwynedd LL57 2UW, UK. ${ }^{4}$ School of Natural Sciences and Psychology, Liverpool John Moores University, James Parsons Building, Byrom Street, Liverpool L3 3AF, UK.

Received: 24 July 2013 Accepted: 28 January 2014

Published: 3 March 2014

\section{References}

1. NWWG: Wetlands of Canada: Ecological Land Classification Series No. 24. Ottowa: Environment Canada; 1988.

2. Lavoie M, Paré D, Bergeron Y: Impact of global change and forest management on carbon sequestration in northern forested peatlands. Environ Rev 2005, 13:199-240.

3. Grønlund A, Sveistrup TE, Sovik AK, Rasse DP, Klove B: Degradation of cultivated peat soils in Northern Norway based on field scale $\mathrm{CO}_{2}, \mathrm{~N}_{2} \mathrm{O}$ and $\mathrm{CH}_{4}$ emission measurements. Arch Agron Soil Sci 2006, 52:149-159.

4. Treat C, Turetsky M, Harden J, McGuire A: Methane emissions from boreal peatlands in a changing climate: quantifying the sensitivity of methane fluxes to experimental manipulations of water table and soil temperature regimes in an Alaskan boreal fen. AGU Fall Meeting Abstracts 2006, 1:1191.

5. Vitt DH, Halsey LA, Bauer IE, Campbell C: Spatial and temporal trends in carbon storage of peatlands of continental western Canada through the Holocene. Can J Earth Sci 2000, 37:683-693.

6. Yu Z, Campbell ID, Vitt DH, Apps MJ: Modelling long-term peatland dynamics: I: concepts, review, and proposed design. Ecol Model 2001, 145:197-210.

7. Gorham E: Northern peatlands: role in the carbon cycle and probable responses to climatic warming. Ecol Appl 1991, 1:182-195.

8. Martikainen PJ, Nykänen H, Crill P, Silvola J: Effect of a lowered water table on nitrous oxide fluxes from northern peatlands. Nature 1993, 366:51-53.

9. Freeman C, Lock M, Reynolds B: Fluxes of carbon dioxide, methane and nitrous oxide from a Welsh peatland following simulation of water table draw-down: potential feedback to climatic change. Biogeochemistry 1993, 19:51-60.

10. Nykänen $\mathrm{H}$, Alm J, Lång $\mathrm{K}$, Silvola J, Martikainen PJ: Emissions of $\mathrm{CH}_{4}, \mathrm{~N}_{2} \mathrm{O}$ and $\mathrm{CO}_{2}$ from a virgin fen and a fen drained for grassland in Finland. J Biogeogr 1995, 22:351-357.

11. Hendriks DMD, van Huissteden J, Dolman AJ, van der Molen MK: The full greenhouse gas balance of an abandoned peat meadow. Biogeosciences 2007, 4:411-424.

12. Moore $T$, Knowles $R$ : The influence of water table levels on methane and carbon dioxide emissions from peatland soils. Can J Soil Sci 1989, 69:33-38.

13. Moore T, Roulet N: Methane flux: water table relations in northern wetlands. Geophys Res Lett 1993, 20:587-590.

14. Couwenberg J, Thiele A, Tanneberger F, Augustin J, Bärisch S, Dubovik D, Liashchynskaya N, Michaelis D, Minke M, Skuratovich A, Joosten H: Assessing greenhouse gas emissions from peatlands using vegetation as a proxy. Hydrobiologia 2011, 674:67-89.

15. Gallego-Sala AV, Prentice IC: Blanket peat biome endangered by climate change. Nat Clim Chang 2013, 3:152-155.

16. Worrall F, Chapman P, Holden J, Evans C, Artz R, Smith P, Grayson R: A review of current evidence on carbon fluxes and greenhouse gas emissions from UK peatlands. UK: Report to JNCC; 2011:86.

17. Bonn A, Holden J, Parnell M, Worrall F, Chapman P, Evans C, Termansen M, Beharry-Borg N, Acreman M, Rowe E, et al: Ecosystem services of peat - Phase 1: Final report. UK: Defra project Report SP0572; 2009:141.

18. JNCC: Towards an assessment of the state of UK peatlands: JNCC Report No. 445. Peterborough: JNCC; 2011.

19. Baird A, Holden J, Chapman P: A literature review of evidence on emissions of methane in peatlands. University of Leeds; UK: Defra Project SP0574; 2009:54.

20. Evans C, Worrall F, Holden J, Chapman P, Smith P, Artz R: A programme to address evidence gaps in greenhouse gas and carbon fluxes from UK peatlands. UK: Report to JNCC; 2011:52.

21. Gustavsen HG, Heinonen R, Paavilainen E, Reinikainen A: Growth and yield models for forest stands on drained peatland sites in southern Finland. For Ecol Manage 1998, 107:1-17. 
22. Charman DJ, Warner BG: Peatlands and environmental change. Chichester: John Wiley \& Sons Ltd; 2002.

23. Dumanski J: Carbon sequestration, soil conservation, and the Kyoto Protocol: summary of implications. Clim Change 2004, 65:255-261.

24. IPCC: Supplement to the 2006 IPCC Guidelines for National Greenhouse Gas Inventories: Wetlands. in press.

25. Bussell J, Jones D, Healey J, Pullin A: In How do draining and re-wetting affect carbon stores and greenhouse gas fluxes in peatland soils, Review, CEE review 08-012 (SR49), Collaboration for Environmental Evidence. http://www.environmentalevidence.org/SR49.html 2010.

26. Dalrymple S, Burden A, Evans C, Healey J, Jones D, Pullin AS: In Evaluating effects of management on greenhouse gas fluxes and carbon balances in boreotemperate lowland peatland systems: CEE protocol 11-010, Collaboration for Environmental Evidence. www.environmentalevidence.org/SR11010.html 2012.

27. Cohen J: A coefficient of agreement for nominal scales. Educ Psychol Meas 1960, 20:37-46.

28. Edwards P, Clark M, DiGuiseppi C, Pratap S, Roberts I, Wentz R Identification of randomized controlled trials in systematic reviews: accuracy and reliability of screening records. Stat Med 2002, 21:1635-1640.

29. Tummers B: DataThief III. ; 2006. http://datathief.org/.

30. Forster P, Ramaswamy V, Artaxo P, Berntsen T, Betts R, Fahey DW, Haywood J, Lean J, Lowe DC, Myhre G: Changes in atmospheric constituents and in radiative forcing. In Climate Change 2007: The Physical Science Basis Contribution of Working Group I to the Fourth Assessment Report of the Intergovernmental Panel on Climate Change. Edited by Solomon S, Qin D, Manning M, Chen Z, Marquis M, Averyt K, Tignor M, HL H. Cambridge, UK and New York, USA: Cambridge University Press; 2007.

31. R Development Core Team: $R$ version 2.9. 2. Vienna, Austria: $R$ Project for Statistical Computing; 2009

32. Viechtbauer $\mathrm{W}$ : Conducting meta-analyses in $\mathrm{R}$ with the metafor package. J Stat Softw 2010, 36:1-48.

33. Sterne JAC, Smith GD: Sifting the evidence-what's wrong with significance tests? Phys Ther 2001, 81:1464-1469.

34. Lewis S, Clarke M: Forest plots: trying to see the wood and the trees. BMJ: Bri Med J 2001, 322:1479

35. Danevčič T, Mandic-Mulec I, Stres B, Stopar D, Hacin J: Emissions of $\mathrm{CO}_{2}$ $\mathrm{CH}_{4}$ and $\mathrm{N}_{2} \mathrm{O}$ from Southern European peatlands. Soil Biol Biochem 2010, 42:1437-1446.

36. Kløve B, Sveistrup TE, Hauge A: Leaching of nutrients and emission of greenhouse gases from peatland cultivation at Bodin, Northern Norway. Geoderma 2010, 154:219-232.

37. Lund M, Christensen TR, Mastepanov M, Lindroth A, Ström L: Effects of N and $P$ fertilization on the greenhouse gas exchange in two northern peatlands with contrasting $\mathrm{N}$ deposition rates. Biogeosciences 2009, 6:2135-2144.

38. Maljanen $\mathrm{M}$, Hytönen J, Martikainen PJ: Fluxes of $\mathrm{N}_{2} \mathrm{O}, \mathrm{CH}_{4}$ and $\mathrm{CO}_{2}$ on afforested boreal agricultural soils. Plant Soil 2001, 231:113-121.

39. Maljanen M, Hytönen J, Martikainen PJ: Cold-season nitrous oxide dynamics in a drained boreal peatland differ depending on land-use practice. Can J Forest Res-Revue Canadienne De Recherche Forestiere 2010, 40:565-572.

40. Petersen SO, Hoffmann CC, Schäfer CM, Blicher-Mathiesen G, Elsgaard L, Kristensen K, Larsen SE, Torp SB, Greve MH: Annual emissions of $\mathrm{CH}_{4}$ and $\mathrm{N}_{2} \mathrm{O}$, and ecosystem respiration, from eight organic soils in Western Denmark managed by agriculture. Biogeosci Discuss 2011, 8:10017-10067.

41. Regina K, Nykänen $\mathrm{H}$, Silvola J, Martikainen PJ: Fluxes of nitrous oxide from boreal peatlands as affected by peatland type, water table level and nitrification capacity. Biogeochemistry 1996, 35:401-418.

42. Strack M, Waddington JM, Rochefort L, Tuittila ES: Response of vegetation and net ecosystem carbon dioxide exchange at different peatland microforms following water table drawdown. J Geophys Res-Biogeosci 2006, 111:G2.

43. Strack M, Waddington JM, Lucchese MC, Cagampan JP: Moisture controls on $\mathrm{CO}_{2}$ exchange in a Sphagnum-dominated peatland: results from an extreme drought field experiment. Ecohydrology 2009, 2:454-461.

44. Silvola J, Alm J, Ahlholm U, Nykänen $\mathrm{H}$, Martikainen PJ: $\mathrm{CO}_{2}$ fluxes from peat in boreal mires under varying temperature and moisture conditions. J Ecol 1996, 84:219-228.

45. Nykänen H, Alm J, Silvola J, Tolonen K, Martikainen PJ: Methane fluxes on boreal peatlands of different fertility and the effect of long-term experimental lowering of the water table on flux rates. Global Biogeochem Cycles 1998, 12:53-69.
46. Von Arnold K, Weslien P, Nilsson M, Svensson BH, Klemedtsson L: Fluxes of $\mathrm{CO}_{2}, \mathrm{CH}_{4}$ and $\mathrm{N}_{2} \mathrm{O}$ from drained coniferous forests on organic soils. For Ecol Manage 2005, 210:239-254.

47. Strack M, Waddington JM: Response of peatland carbon dioxide and methane fluxes to a water table drawdown experiment. Global Biogeochem Cycles 2007, 21:GB1007.

48. Minkkinen K, Laine J: Vegetation heterogeneity and ditches create spatial variability in methane fluxes from peatlands drained for forestry. Plant Soil 2006, 285:289-304.

49. Strack M, Waddington JM, Tuittila ES: Effect of water table drawdown on northern peatland methane dynamics: implications for climate change. Global Biogeochem Cycles 2004, 18:GB4003.

50. Moore TR, Clarkson BR: Dissolved organic carbon in New Zealand peatlands. N Z J Mar Freshw Res 2007, 41:137-141.

51. Glatzel S, Kalbitz K, Dalva M, Moore T: Dissolved organic matter properties and their relationship to carbon dioxide efflux from restored peat bogs. Geoderma 2003, 113:397-411.

52. Banaś K, Gos K: Effect of peat-bog reclamation on the physico-chemical characteristics of the ground water in peat. Pol J Ecol 2004, 52:69-74.

53. Fiedler S, Höll BS, Freibauer A, Stahr K, Drösler M, Schloter M, Jungkunst HF: Particulate organic carbon (POC) in relation to other pore water carbon fractions in drained and rewetted fens in Southern Germany. Biogeosciences 2008, 5:1615-1623.

54. Strack M, Waddington JM, Bourbonniere RA, Buckton EL, Shaw K, Whittington P, Price JS: Effect of water table drawdown on peatland dissolved organic carbon export and dynamics. Hydrol Process 2008, 22:3373-3385.

55. Soini $P$, Riutta $T$, Yli-Petäys $M$, Vasander $H$ : Comparison of vegetation and $\mathrm{CO}_{2}$ dynamics between a restored cut-away peatland and a Pristine Fen: evaluation of the restoration success. Restor Ecol 2010, 18:894-903.

56. Komulainen VM, Nykänen H, Martikainen PJ, Laine J: Short-term effect of restoration on vegetation change and methane emissions from peatlands drained for forestry in southern Finland. Can J Forest Res 1998, 28:402-411.

57. Tuittila ES, Komulainen VM, Vasander H, Nykänen H, Martikainen PJ, Laine J: Methane dynamics of a restored cut-away peatland. Glob Chang Biol 2000, 6:569-581

58. Waddington JM, Day SM: Methane emissions from a peatland following restoration. J Geophys Res-Biogeosciences 2007, 112:G3.

59. Kalbitz K, Rupp H, Meissner R: N, P- and DOC-dynamics in soil and groundwater after restoration of intensively cultivated fens; 2002.

60. Höll BS, Fiedler S, Jungkunst HF, Kalbitz K, Freibauer A, Drösler M, Stahr K: Characteristics of dissolved organic matter following 20 years of peatland restoration. Sci Total Environ 2009, 408:78-83.

61. Cagampan JP, Waddington JM: Net ecosystem $\mathrm{CO}_{2}$ exchange of a cutover peatland rehabilitated with a transplanted acrotelm. Ecoscience 2008, 15:258-267.

62. Augustin J, Merbach W, Steffens L, Snelinski B: Nitrous oxide fluxes of disturbed minerotrophic peatlands. Agribiol Res-Zeitschrift Fur Agrarbiologie Agrikulturchemie Okologie 1998, 51:47-57.

63. van Beek CL, Pleijter M, Jacobs CMJ, Velthof GL, van Groenigen JW, Kuikman PJ: Emissions of $\mathrm{N}_{2} \mathrm{O}$ from fertilized and grazed grassland on organic soil in relation to groundwater level. Nutr Cycl Agroecosyst 2010, 86:331-340.

64. van Beek CL, Pleijter M, Kuikman PJ: Nitrous oxide emissions from fertilized and unfertilized grasslands on peat soil. Nutr Cycl Agroecosyst 2011, 89:453-461.

65. Velthof GL, Oenema $\mathrm{O}$ : Nitrous oxide fluxes from grassland in the Netherlands: II. Effects of soil type, nitrogen fertilizer application and grazing. Eur J Soil Sci 1995, 46:541-549.

66. van den Pol-van Dasselaar A, van Beusichem ML, Oenema O: Effects of nitrogen input and grazing on methane fluxes of extensively and intensively managed grasslands in the Netherlands. Biol Fertil Soils 1999 29:24-30.

67. van den Pol-van Dasselaar A, van Beusichem ML, Oenema O: Effects of grassland management on the emission of methane from intensively managed grasslands on peat soil. Plant Soil 1997, 189:1-9.

68. Dirks BOM, Hensen A, Goudriaan J: Effect of drainage on $\mathrm{CO}_{2}$ exchange patterns in an intensively managed peat pasture. Climate Res 2000, 14:57-63.

69. Godin A, McLaughlin JW, Webster KL, Packalen M, Basiliko N: Methane and methanogen community dynamics across a boreal peatland nutrient gradient. Soil Biol Biochem 2012, 48:96-105.

70. Webster KL: Importance of the Water Table in Controlling Dissolved Carbon along a Fen Nutrient Gradient [electronic resource]; 2010. 
71. Rochette P, Tremblay N, Fallon E, Angers DA, Chantigny MH, MacDonald JD, Bertrand N, Parent LE: $\mathrm{N}_{2} \mathrm{O}$ emissions from an irrigated and non-irrigated organic soil in eastern Canada as influenced by $\mathrm{N}$ fertilizer addition. Eur $\mathrm{J}$ Soil Sci 2010, 61:186-196.

72. Hyvönen NP, Huttuneen JT, Shurpali NJ, Tavi NM, Repo ME, Martikainen PJ: Fluxes of nitrous oxide and methane on an abandoned peat extraction site: effect of reed canary grass cultivation. Bioresour Technol 2009, 100:4723-4730.

73. Glenn S, Heyes A, Moore T: Carbon-dioxide and methane fluxes from drained peat soils, Southern Quebec. Global Biogeochem Cycles 1993, 7:247-257.

74. Mäkiranta P, Hytönen J, Aro L, Maljanen M, Pihlatie M, Potila H, Shurpali NJ, Laine J, Lohila A, Martikainen PJ, Minkkinen K: Soil greenhouse gas emissions from afforested organic soil croplands and cutaway peatlands. Boreal Environ Res 2007, 12:159-175.

75. Waddington JM, Warner KD, Kennedy GW: Cutover peatlands: a persistent source of atmospheric $\mathrm{CO}_{2}$. Global Biogeochem Cycles 2002, 16(1):GB001298.

76. Nagata O, Yazaki T, Yanai Y: Nitrous oxide emissions from drained and mineral soil-dressed peatland in central Hokkaido, Japan. J Agric Meteorol 2010, 66:23-30.

77. Rupp $H$, Meissner R, Leinweber P: Effects of extensive land use and re-wetting on diffuse phosphorus pollution in fen areas-results from a case study in the Drömling catchment, Germany. J Plant Nutr Soil Sci 2004, 167:408-416.

78. Clymo R: Peat. In General Studies Ecosystems of the world 4A Mires: Swamp, Bog, Fen and Moor. Edited by Gore AJP. Amsterdam: Elsevier; 1983:159-224.

79. Charman D: Peatlands and environmental change. Chichester: John Wiley \& Sons Ltd; 2002.

80. Bremner J, Blackmer A: Nitrous oxide: emission from soils during nitrification of fertilizer nitrogen. Science 1978, 199:295-296.

81. Perneger TV: What's wrong with Bonferroni adjustments. BMJ 1998, 316:1236-1238.

82. Kortelainen P, Saukkonen S: Leaching of organic carbon and nitrogen from forested catchments. In The Finnish research programme on climate change, second progress report. Volume 1/94. Edited by Kanninen M, Heikinheimo P. Publications of the Academy of Finland; 1994:285-290.

83. Hooijer A, Page S, Jauhiainen J, Lee W, Lu X, Idris A, Anshari G: Subsidence and carbon loss in drained tropical peatlands: reducing uncertainty and implications for $\mathrm{CO}_{2}$ emission reduction options. Biogeosciences Discuss 2011, 8:9311-9356. doi: 10.5194/bgd-8-9311-2011.

84. Waltham T: Peat subsidence at the Holme post. Mercian Geol 2000, 15:49-51.

85. Morrison R, Cumming A, Taft H, Kaduk J, Page S, Jones D, Harding R, Balzter H: Carbon dioxide fluxes at an intensively cultivated temperate lowland peatland in the East Anglian Fens, UK. Biogeosci Discuss 2013, 10:4193-4223.

doi:10.1186/2047-2382-3-5

Cite this article as: Haddaway et al:: Evaluating effects of land management on greenhouse gas fluxes and carbon balances in boreo-temperate lowland peatland systems. Environmental Evidence 2014 3:5.

\section{Submit your next manuscript to BioMed Central and take full advantage of:}

- Convenient online submission

- Thorough peer review

- No space constraints or color figure charges

- Immediate publication on acceptance

- Inclusion in PubMed, CAS, Scopus and Google Scholar

- Research which is freely available for redistribution 